\title{
Monetary Policy and Exchange Rates: \\ A Balanced Two-Country Cointegrated VAR Model Approach
}

\author{
Reinhold Heinlein*1,2 and Hans-Martin Krolzig ${ }^{1}$ \\ ${ }^{1}$ School of Economics, University of Kent, Keynes College, Canterbury CT2 7NP \\ ${ }^{2}$ Keele Management School, Keele University, Darwin Building, Staffordshire ST5 5BG
}

December 2016

\begin{abstract}
We study the exchange rate effects of monetary policy in a balanced macroeconometric two-country model for the US and UK. In contrast to the empirical literature on the 'delayed overshooting puzzle', which consistently treats the domestic and foreign countries unequally in the modelling process, we consider the full model feedback, allowing for a thorough analysis of the system dynamics. The consequential inevitable problem of model dimensionality is tackled in this paper by invoking the approach by Aoki (1981) commonly used in economic theory. Assuming country symmetry in the long-run allows to decouple the two-country macro dynamics of country averages and country differences such that the cointegration analysis can be applied to much smaller systems. Secondly the econometric modelling is general-to-specific, a graph-theoretic approach for the contemporaneous effects combined with an automatic general-to-specific model selection. The resulting parsimonious structural vector equilibrium correction model ensures highly significant impulse responses, revealing a delayed overshooting of the exchange rate in the case of a Bank of England monetary shock but suggests an instantaneous response to a Fed shock. Altogether the response is more pronounced in the former case.
\end{abstract}

Keywords: Two-country model; Cointegration; Structural VAR; Gets Model Selection; Monetary Policy; Exchange Rates.

JEL classification: C22; C32; C50.

\footnotetext{
${ }^{*}$ Corresponding author, email: r.heinlein@ keele.ac.uk (R. Heinlein). We are grateful to Ralf Brüggemann, Sascha Buetzer, Miguel León-Ledesma, Helmut Lütkepohl and the seminar audiences at Kent, University of Konstanz, DIW Macroeconometric Workshop 2011, Berlin, SNDE Symposium 2012, Istanbul, the ICMAIF 2012, Rethymno, the VfS Congress 2012, Göttingen, the RCEA Time Series Workshop 2013, Rimini and the IAAE 2014, London. The usual disclaimer applies.
} 


\section{Introduction}

In this paper we propose a modelling strategy for empirical two-country models. The main contribution of the paper is a specification for the long-run of the model in sub-systems to deal with the curse of dimensionality. For this, an idea of Aoki (1981), frequently applied in economic theory, is introduced into empirical research. Further, a graph-theoretic approach for the short run and a general-to-specific model selection procedure is applied. Additionally to the selection of a best model, model pooling is performed to assure robustness.

We employ our modelling strategy to analyse the effects of monetary policy on exchange rates. We set up a balanced macroeconometric two-country model for the US and the UK and analyse the responses of the Dollar/Pound exchange rate to monetary policy shocks in both countries. This analysis contributes to the literature of the delayed overshooting puzzle. Eichenbaum and Evans (1995) found a delayed response of the exchange rate following a monetary policy shock, what is at odds to relevant theory contributions like Dornbusch (1976) and Frankel (1979). Several research papers followed up on this surprising result finding mixed outcomes, some confirming the delayed response like Scholl and Uhlig (2008), Bouakez and Normandin (2010), Heinlein and Krolzig (2012), while others observe a jump of the exchange rate on impact in line with the uncovered interest rate parity prediction like Cushman and Zha (1997), Kim and Roubini (2000), Bjørnland (2009).

Table 1 Choice of model variables and shocks in the VAR-based literature on the delayed-overshooting hypothesis

\begin{tabular}{|c|c|c|c|c|}
\hline & US & Non-US & FX & Shocks \\
\hline \multirow[t]{3}{*}{ Eichenbaum and Evans (1995) } & $p, y, R^{X}$ & $i-i^{u S}$ & $s(e)$ & $R^{X, u s}$ \\
\hline & $p, y, R^{X}, i$ & $y, i$ & $s(e)$ & $R^{X, u s}, i^{u s}$ \\
\hline & $p, y, R^{X}, i^{f}$ & $y, i$ & $s$ & $R^{R, u s}$ \\
\hline \multirow[t]{3}{*}{ Grilli and Roubini (1996) } & $\pi, y, i$ & $\pi, y, i$ & $e$ & $i$ \\
\hline & $\pi, y, i$ & $\pi, y, r-i$ & $e(s)$ & $r-i$ \\
\hline & $i$ & $p, y, m, i, p^{o}$ & $e$ & $i$ \\
\hline Cushman and Zha (1997) & $p, y, i^{f}$ & $p, y, m, i, E x, \operatorname{Im}, p^{c}$ & $e$ & $m$ \\
\hline Kim and Roubini (2000) & $i^{f}$ & $p, y, m, i, p^{o}$ & $e(s)$ & $i, i^{f, u s}$ \\
\hline \multirow[t]{2}{*}{ Faust and Rogers (2003) } & $p, y, R^{X}, i$ & $y, i$ & $e$ & $R^{X, u s}$ \\
\hline & $p, y, R^{N}, R^{T}, m, i, r$ & $p, y, m, i, r, p^{c}$ & $e$ & $R^{N, u s}$ \\
\hline Scholl and Uhlig (2008) & $p, y, R^{X}, i$ & $y, i$ & $e$ & $R^{X, u s}$ \\
\hline \multirow[t]{2}{*}{ Bjørnland (2009) } & $i^{w}$ & $\pi, y, i$ & $\Delta s^{w}$ & $i$ \\
\hline & $i^{w}$ & $\pi, y, i, p^{o}$ & $\Delta s^{w}$ & $i$ \\
\hline Voss and Willard (2009) & $p, y, u, m, i^{f}$ & $p, y, i, p^{c}$ & $e(s)$ & $i, i^{f, u s}$ \\
\hline \multirow[t]{2}{*}{ Bouakez and Normandin (2010) } & $p, y, R^{N}, R^{T}, i^{f}$ & $i-i^{u s}, p^{c}$ & $e$ & $R^{N, u s}$ \\
\hline & $p, y, R^{N}, R^{T}, i^{f}, i$ & $p, y, i, p^{c}$ & $e$ & $R^{N, u s}$ \\
\hline Heinlein and Krolzig (2012) & \multicolumn{2}{|c|}{$\pi-\pi^{u s}, \Delta y-\Delta y^{u s}, i-i^{u s}, r-r^{u s}$} & $e$ & $i-i^{u s}$ \\
\hline
\end{tabular}

The papers in this literature usually apply an unbalanced approach by modelling only one country in detail, while the other country is often only represented by a policy instrument, see the specifications of relevant literature in Table $1^{1}$. The reason for this is to keep the number of variables in the model

\footnotetext{
${ }^{1}$ Kim et al. (2014) revisit different model specifications, mainly Scholl and Uhlig (2008), by focussing on sub-periods. They find that the phenomenon of delayed overshooting is mostly present in the Volcker era.
} 
small to be tractable. This is problematic as a proper analysis of the system dynamics would demand a balanced approach. A balanced approach is especially of importance, when the two countries are large and the influence is bi-directional. A balanced approach might be of lesser importance when a small country model is applied, like in Cushman and Zha (1997), Bjørnland (2009) and Voss and Willard (2009), where one or several of the following countries have been analysed: Australia, Canada, New Zealand and Sweden relative to the US. Secondly, the papers in this literature usually study a monetary policy shock in one of the two countries only. Monetary policy shocks in both countries are studied in Kim and Roubini (2000) and Voss and Willard (2009), but in both papers in a non-balanced setup. The necessity to analyse monetary policy shocks in the domestic and the foreign country is emphasised by Voss and Willard (2009). Using an unbalanced setup they found that only policy shocks by the Reserve Bank of Australia are affecting the AUD/USD exchange rate significantly. The possibility of asymmetric responses of the US and the other countries is not generally discussed in the literature. ${ }^{2}$ Indeed, the results of the two-country model presented in this paper will show a pronounced asymmetry: a delayed overshooting response of the exchange rate in the case of a Bank of England shock, but an instantaneous jump in the case of a Fed shock. Altogether the exchange rate response is larger in size after an increase of the short-term interest rate in the UK. This asymmetric result illustrates the need for a rigorous analysis of this issue and may shed light on the conflicting results in the literature.

With our proposed modelling strategy we seek to contribute to the knowledge on the delayed overshooting puzzle by improving on the existing literature in four economically and econometrically important aspects:

(i) Lack of balance: The empirical literature on the 'delayed overshooting puzzle' consistently treats the domestic and foreign countries unequally in the modelling process. To allow for a thorough analysis of the system dynamics, the possibility of full model feedback is necessary, with the need for a balanced VAR model. We apply a balanced approach with both economies being modelled with an equally detailed information set. To cope with the problem of dimensionality, we introduce an average-difference approach from economic theory into applied work. This economic modelling approach is a novelty in empirical research and might prove as a very successful tool in building two-country models. Further, we identify the long-run and the short-run empirically, with homogeneous treatment of the two countries. Finally, we study shocks with an origin in each of the two countries. This allows to detect differences in responses, which are purely data driven and not predetermined by the model set-up.

(ii) Lack of a well-specified long-run: Despite the involvement of possibly integrated time series, most of the relevant literature employs VAR models in levels. By commencing from an unrestricted cointegrated VAR model and developing a parsimonious structural vector equilibrium correction model, which is the adequate $I(0)$ representation of the system, we will be able to carefully study the long-run and short-run properties of the macroeconomic time series.

(iii) Ad-hoc modelling/Specification of instantaneous causality: Since the seminal contribution of Eichenbaum and Evans (1995), there has been an intense discussion about the arbitrary assumptions leading to the identification of the direction of instantaneous causality. Many of the proposed

\footnotetext{
${ }^{2}$ Linnemann and Schabert (2015) find with their theoretical model a delayed response of the exchange rate mainly for a monetary policy shock originated in the US, what they explain with liquidity premia on short-term treasuries.
} 
alternative schemes are based on theoretical ad-hoc assumptions. In this paper, we seek to overcome these limitations by taking advantage of recent advances in graph theory and its application to the search for causality among variables. When the applied algorithm is not capable of finding a directed acyclical graph, i.e. a causal chain, we use information criteria for selecting or pooling to facilitate the policy experiment.

(iv) Curse of dimensionality: Highly parameterized unrestricted VAR or just-identified structural VAR models require the estimation of a large number of parameters with the majority being irrelevant, the degrees of freedom being exhausted and estimation uncertainty inflated. The impulse responses become inconclusive due to a growing width of confidence intervals, which will eventually include the zero line. To avoid this problem we make use of automatic general-to-specific model reduction procedures reducing the complexity of the model while preserving the characteristics of the data. Also, the graph-theoretic approach to identify the direction of the instantaneous causality generally delivers testable overidentifying restrictions and hence reduces the number of parameters. Altogether we construct a overidentified parsimonious structural vector equilibrium correction model for a statistically precise and economically meaningful impulse response analysis.

This paper follows up on an earlier paper of the same authors with a similar empirical research question (Heinlein and Krolzig, 2012). The earlier paper applies a symmetric approach, where differences between the domestic and foreign variables enter the model. This way the responses of the exchange rate to monetary shocks in both countries are always identical with opposite signs. In this newer paper we relax the symmetry assumption for the contemporaneous effects, for the short-run dynamics and for the speed of adjustment to the long-run. The earlier model has been working with quarterly data while this paper uses monthly data frequency. The same cointegrating relationships have been found in the country difference model, what is very reassuring.

A main contribution of this paper is the introduction of a dimension reduction procedure for empirical two-country models. Cointegrated VAR models are restricted to a small number of variables. With an increase in the dimension of the model it is getting very difficult to impose meaningful structure on the unrestricted cointegration relations. Aoki (1981) showed for a system of linear differential equations that, when assuming symmetry on the two-country model, the variables can be transformed into a set of country averages and country differences and these two sets being orthogonal to each other, can be analysed separately. What has been developed for a continuous-time deterministic set-up, we apply now to a discrete-time stochastic model. This approach can be used for any VAR model. In our empirical application symmetry is confirmed for the long-run, therefore we allow for asymmetry in the short-run, applying this approach for the detection of the cointegration relationships only.

The idea of breaking the analysis of a system down into submodels, is related to the integrated model approach of Juselius (2006) and the GVAR approach of Pesaran et al. (2004). In the integrated model of Juselius (2006), the long-run structures of different sectors are analysed separately and then combined to a complete model. Inflation is modelled by combining submodels representing the money market, the external sector and the labour market. In the GVAR approach country-specific models are specified including the domestic economy and country-specific global variables. A large number of individual country models are linked together usually via a trade weighted matrix, to form the global system. 
The structure of the paper is as follows. In $\S 2$ we present the methodological aspects of the economic modelling approach and the econometric model selection procedure. In $\S 3$ we introduce the data set. The formation of the-two-country model is discussed in $\S 4$ for the long-run and in $\S 5$ for the full 9dimensional system. $\$ 6$ investigates the effects of monetary policy shocks with focus on the presence of a delayed overshooting puzzle. Finally $\$ 7$ concludes.

\section{Methodology}

Our modelling approach proceeds in two major steps. In the first step we determine the long-run of the model. For this, we introduce a method to separate the cointegration space in two smaller sub-sets. In the second step of the modelling approach the short-run of the model is developed in the full 9-dimensional system.

\subsection{Analysis of the two-country long-run relations using the Aoki method}

We are utilising a modelling approach by Aoki (1981) frequently used in economic theory in a dynamic macroeconometric two-country model. Masanao Aoki showed that for a system of linear differential equations, the assumption of country symmetry allows to decouple the dynamics of the system into two autonomous subsystems of country averages and country differences. In Krolzig and Heinlein (2013) we generalize Aoki's approach to a stochastic setup in discrete time. In this paper we demonstrate how it can be used for the analysis of the long-run of a large dynamic system.

\subsubsection{Separation into country differences and country averages}

Suppose we have two countries and our focus is on a balanced set of $K$ key macroeconomic variables for both economies, respectively, and their exchange rate. Let $\boldsymbol{y}_{t}$ be the $K \times 1$ vector of domestic variables, $\boldsymbol{y}_{t}^{*}$ the $K \times 1$ vector of the same variables for the foreign country, and $e_{t}$ denotes the exchange rate. The full system vector $\boldsymbol{x}_{t}=\left(\boldsymbol{y}_{t}, \boldsymbol{y}_{t}^{*}, e_{t}\right)^{\prime}$ is hence $2 K+1$ dimensional.

Following Aoki (1981) the set of domestic-foreign variables is transformed into a set of countryaverage-difference variables:

$$
\boldsymbol{y}_{t}^{a}=\frac{1}{2}\left(\boldsymbol{y}_{t}+\boldsymbol{y}_{t}^{*}\right) \quad \text { and } \quad \boldsymbol{y}_{t}^{d}=\boldsymbol{y}_{t}-\boldsymbol{y}_{t}^{*}
$$

The system $\tilde{\boldsymbol{x}}_{t}=\left(\boldsymbol{y}_{t}^{a}, \boldsymbol{y}_{t}^{d}, e_{t}\right)^{\prime}$ is a linear isomorphic transformation of the system $\boldsymbol{x}_{t}=\left(\boldsymbol{y}_{t}, \boldsymbol{y}_{t}^{*}, e_{t}\right)^{\prime}$. Defining $\tilde{\boldsymbol{x}}_{t}^{a} \equiv \boldsymbol{y}_{t}^{a}$ and $\tilde{\boldsymbol{x}}_{t}^{d} \equiv\left(\boldsymbol{y}_{t}^{d}, e_{t}\right)^{\prime}$, the two-country $\operatorname{CVAR}(p)$ model in its country-averages-differences VECM form without deterministic terms looks like follows:

$$
\begin{aligned}
{\left[\begin{array}{c}
\Delta \tilde{\boldsymbol{x}}_{t}^{a} \\
\Delta \tilde{\boldsymbol{x}}_{t}^{d}
\end{array}\right]=} & {\left[\begin{array}{ll}
\boldsymbol{\alpha}_{a a} & \boldsymbol{\alpha}_{a d} \\
\boldsymbol{\alpha}_{d a} & \boldsymbol{\alpha}_{d d}
\end{array}\right]\left[\begin{array}{cc}
\boldsymbol{\beta}_{a a}^{\prime} & \boldsymbol{\beta}_{a d}^{\prime} \\
\boldsymbol{\beta}_{d a}^{\prime} & \boldsymbol{\beta}_{d d}^{\prime}
\end{array}\right]\left[\begin{array}{c}
\tilde{\boldsymbol{x}}_{t-1}^{a} \\
\tilde{\boldsymbol{x}}_{t-1}^{d}
\end{array}\right]+\sum_{i=1}^{p-1}\left[\begin{array}{ll}
\boldsymbol{\Gamma}_{a a, i} & \boldsymbol{\Gamma}_{a d, i} \\
\boldsymbol{\Gamma}_{d a, i} & \boldsymbol{\Gamma}_{d d, i}
\end{array}\right]\left[\begin{array}{c}
\Delta \tilde{\boldsymbol{x}}_{t-i}^{a} \\
\Delta \tilde{\boldsymbol{x}}_{t-i}^{d}
\end{array}\right]+\left[\begin{array}{c}
\boldsymbol{u}_{t}^{a} \\
\boldsymbol{u}_{t}^{d}
\end{array}\right], } \\
\text { where } & {\left[\begin{array}{l}
\boldsymbol{u}_{t}^{a} \\
\boldsymbol{u}_{t}^{d}
\end{array}\right] \sim \operatorname{IID}\left(\left[\begin{array}{l}
\mathbf{0} \\
\mathbf{0}
\end{array}\right],\left[\begin{array}{ll}
\boldsymbol{\Sigma}_{a a} & \boldsymbol{\Sigma}_{a d} \\
\boldsymbol{\Sigma}_{d a} & \boldsymbol{\Sigma}_{d d}
\end{array}\right]\right) . }
\end{aligned}
$$

As in Aoki (1981), symmetry of the two countries implies separapility into two autonomous subsystems 
$\tilde{\boldsymbol{x}}_{t}^{a}$ and $\tilde{\boldsymbol{x}}_{t}^{d}$. Symmetry requires block-diagonality of all parameter matrices in (2):

(i) $\boldsymbol{\beta}_{a d}=\boldsymbol{\beta}_{d a}=\mathbf{0}$,

(ii) $\boldsymbol{\alpha}_{a d}=\boldsymbol{\alpha}_{d a}=\mathbf{0}$,

(iii) $\boldsymbol{\Gamma}_{a d, i}=\boldsymbol{\Gamma}_{d a, i}=\mathbf{0}$ for all $i=1, \ldots, p-1$ and

(iv) $\boldsymbol{\Sigma}_{a d}=\boldsymbol{\Sigma}_{d a}=\mathbf{0}$.

It is worth noting that we assume symmetry for the long-run only. In the final full two-country model, only the first assumption $\boldsymbol{\beta}_{a d}=\boldsymbol{\beta}_{d a}=\mathbf{0}$ will remain. After analysing the two subsystems we will run thorough tests for the validity of the symmetry assumption. We will also investigate the degree of symmetry in the adjustment process, the short-run dynamics and the contemporaneous effects.

\subsubsection{Identification of the cointegration relations among country differences and country aver- ages}

We study the long-run of our model using a likelihood based approach to the cointegration analysis of the two subsystems of country differences and country averages.

(i) Specification of the general unrestricted system of country differences and country averages.

We commence from a $p$-th order reduced-form vector autoregressive (VAR) model without any equation-specific restrictions to capture the characteristics of the data:

$$
\tilde{\boldsymbol{x}}_{t}^{s}=\boldsymbol{\nu}^{s}+\sum_{j=1}^{p} \boldsymbol{A}_{j}^{s} \tilde{\boldsymbol{x}}_{t-j}^{s}+\boldsymbol{u}_{t}^{s}
$$

where $\boldsymbol{u}_{t}^{s} \sim \operatorname{NID}(\mathbf{0}, \boldsymbol{\Sigma})$ is a Gaussian white noise process and $s=a, d$ are country average variables or country differences. This step involves the specification of the deterministic terms, selection of the lag length $p$ and misspecification test to check the validity of the assumptions made.

(ii) Johansen cointegration tests and identification of the cointegration vectors.

The Johansen procedure for determining the cointegration rank, $r$, is then applied to the system (3) mapped into its vector equilibrium-correction mechanism (VECM) representation:

$$
\Delta \tilde{\boldsymbol{x}}_{t}^{s}=\boldsymbol{\nu}^{s}+\boldsymbol{\Pi}^{s} \tilde{\boldsymbol{x}}_{t-1}^{s}+\sum_{j=1}^{p-1} \boldsymbol{\Gamma}_{j}^{s} \Delta \tilde{\boldsymbol{x}}_{t-j}^{s}+\boldsymbol{u}_{t}^{s} .
$$

For a cointegrated vector process, the reduced-rank matrix, $\Pi^{s}$, can be decomposed into loading matrix, $\boldsymbol{\alpha}^{s}$, and cointegration matrix, $\boldsymbol{\beta}^{s}$, containing the information of the long-run structure of the model. The Johansen procedure delivers unique estimates of $\boldsymbol{\alpha}^{s}$ and $\boldsymbol{\beta}^{s}$ as a result of requiring $\boldsymbol{\beta}^{s}$ to be orthogonal and normalized. These estimates provide a value for the unrestricted loglikelihood function to be compared to the log-likelihood under economically meaningful overidentifying restrictions, $\boldsymbol{\beta}^{s, r}$ :

$$
\Delta \tilde{\boldsymbol{x}}_{t}^{s}=\boldsymbol{\nu}^{s}+\boldsymbol{\alpha}^{s} \boldsymbol{\beta}^{s, r^{\prime}} \tilde{\boldsymbol{x}}_{t-1}^{s}+\sum_{j=1}^{p-1} \boldsymbol{\Gamma}_{j}^{s} \Delta \tilde{\boldsymbol{x}}_{t-j}^{s}+\boldsymbol{u}_{t}^{s},
$$


with $\mathrm{E}\left[\boldsymbol{u}_{t}^{s}\right]=0$ and $\mathrm{E}\left[\boldsymbol{u}_{t}^{s} \boldsymbol{u}_{t}^{s^{\prime}}\right]=\hat{\boldsymbol{\Sigma}}^{s}$. The empirical modeling procedure for finding the cointegration relations follows Juselius (2006).

\subsection{Analysis of the two-country vector equilibrium correction model}

After having analysed the long-run in two subsystems we return for the further modelling to the full 9D system:

$$
\Delta \boldsymbol{x}_{t}=\boldsymbol{\nu}+\alpha\left(\begin{array}{c}
\boldsymbol{\beta}^{a, r^{\prime}} \tilde{\boldsymbol{x}}_{t-1}^{a} \\
\boldsymbol{\beta}^{d, r^{\prime}} \tilde{\boldsymbol{x}}_{t-1}^{d}
\end{array}\right)+\sum_{j=1}^{p-1} \boldsymbol{\Gamma}_{j} \Delta \boldsymbol{x}_{t-j}+\boldsymbol{\varepsilon}_{t}, \quad \varepsilon_{t} \sim \operatorname{NID}(\mathbf{0}, \boldsymbol{\Sigma}) .
$$

The modelling strategy we will apply to the VECM above puts particular emphasis on a data-driven identification of the instantaneous causality and a computer-automated model reduction strategy aimed to overcome the curse of dimensionality. It builds upon the work of Demiralp and Hoover (2003), Krolzig (2003), Hoover et al. (2009) and Heinlein and Krolzig (2012). A novel element is the use of model pooling to avoid some of shortcomings resulting from a multi-step procedure. It will also contribute to a quantification of the effects of model uncertainty on the impulse responses.

\subsubsection{Graph-theoretic search for instantaneous causal relations}

The determination of the contemporaneous causal links between the variables has been advanced by modern graph-theoretic methods of searching for causal structure based on relations of conditional independence developed by computer scientists (Pearl, 2000) and philosophers (Spirtes et al., 2001). Following Demiralp and Hoover (2003), who introduced this approach to econometrics, we use the PC algorithm implemented in TETRAD 4 (see Spirtes et al., 2005 for details). The PC algorithm exploits the information embedded in the residual variance-covariance matrix, $\hat{\Sigma}$, of the full 9D system. A causal structure is represented by a graph with arrows from causes to caused variables. To find the directed acyclic graph, the algorithm performs an elimination and an orientation stage.

In the elimination stage, a significance level $\alpha$ for Fisher's Z-statistic is the criterium to decide on correlation between variables. The algorithm starts by assuming that all variables are linked to each other through an undirected link. Firstly connections are removed between two variables which are unconditionally uncorrelated. Then connections are eliminated for variables which are uncorrelated conditional on other variables. Here the correlation of a pair of variables is conditioned on each other variable individually, then on all possible pairs of variables, hereafter on all subsets of three variables and so on up to all possible subsets of conditioning. If there is no more link to be removed the elimination stage is finished and the skeleton of the graph is identified.

This skeleton is the basis for the orientation stage of the algorithm, seeking to direct the undirected edges. Triples of linked variables $A-B-C$ are analysed. If $A \rightarrow B \rightarrow C$ is true, i.e. A causes $\mathrm{B}$ causes $\mathrm{C}$, then $\mathrm{A}$ and $\mathrm{C}$ would be correlated, but independent when conditioned on $\mathrm{B}$. It is said $\mathrm{B}$ screens $\mathrm{A}$ from $\mathrm{C}$. If $A \leftarrow B \rightarrow C$ then $\mathrm{A}$ and $\mathrm{C}$ are again dependent but independent when conditioned on $\mathrm{B}$. Here $\mathrm{B}$ is the common cause of $\mathrm{A}$ and $\mathrm{C}$. An important case is the so called 'unshielded collider'. When $A \rightarrow B \leftarrow C$ is true, $\mathrm{B}$ is an unshielded collider. A and $\mathrm{C}$ are independent when conditioned on possible sets of variables, but dependent when conditioned on $B$. The algorithm systematically searches for unshielded colliders and directs accordingly. Thereafter, remaining undirected edges are observed by logical reasoning. If $A \rightarrow B-C$, where $\mathrm{A}$ and $\mathrm{C}$ are not directly connected, then the later link can 
be only as $B \rightarrow C$. An important final criterium is the search for possible circular relations. Cyclicality of directed graphes is excluded, hence also bidirectional links are not allowed. If there is a directed path leading from $\mathrm{A}$ to $\mathrm{B}$ through other variables and an edge between $\mathrm{A}$ and $\mathrm{B}$, then $A \rightarrow B$ holds. These are the main steps of the orientation stage. It is possible that not all links can be directed.

A directed acyclic graph (DAG) results if all edges could be oriented. Based on the identified contemporaneous causal structure of the system, the 9D VECM can be represented as a recursive structural vector equilibrium correction mechanism (SVECM). By suitable ordering of the variables, the DAG can be mapped to a lower-triangular contemporaneous matrix, $\boldsymbol{B}^{r}$, with units on the diagonal and non-zero lower-off-triangular elements representing the causal links found by the PC algorithm. In contrast to the traditional orthogonalisation with the help of a Choleski decomposition of $\hat{\boldsymbol{\Sigma}}$, this approach results in an overidentified SVECM in the majority of cases. The zero lower-triangular elements of $\boldsymbol{B}^{r}$ provide testable overidentifying constraints allowing to verify the validity of the selected contemporaneous structure. Most importantly, as the contemporaneous causal structure captured by $\boldsymbol{B}^{r}$ is data determined, it avoids the problems associated with the ad-hoc nature of orthogonalised structural VAR models.

\subsubsection{Computer-automated Gets single-equation reductions of the SVECM}

Starting point is the structural VECM with long-run relations $\boldsymbol{\beta}^{s, r}$ determined in $\$ 2.1$ and contemporaneous structure $\boldsymbol{B}^{r}$ given by the corresponding directed acyclic graph:

$$
\boldsymbol{B}^{r} \Delta \boldsymbol{x}_{t}=\boldsymbol{\delta}+\tilde{\boldsymbol{\alpha}}\left(\begin{array}{c}
\boldsymbol{\beta}^{a, r} \tilde{\boldsymbol{x}}_{t-1}^{a} \\
\boldsymbol{\beta}^{d, r^{\prime}} \tilde{\boldsymbol{x}}_{t-1}^{d}
\end{array}\right)+\sum_{j=1}^{p-1} \boldsymbol{\Upsilon}_{j} \Delta \boldsymbol{x}_{t-j}+\boldsymbol{\omega}_{t}, \quad \boldsymbol{\omega}_{t} \sim \operatorname{NID}(\mathbf{0}, \boldsymbol{\Omega}),
$$

where $\boldsymbol{B}^{r}$ is the lower-triangular matrix found by TETRAD and $\Omega$ is a diagonal variance-covariance matrix. A single-equation based Gets reduction procedure such as $P c G e t s$ can be applied to the equations in (7) straightforwardly and, as shown in Krolzig (2003), without a loss in efficiency. The parameters of interest are the coefficients collected in the intercept, $\delta$, the adjustment matrix $\tilde{\boldsymbol{\alpha}}$ and the shortrun matrices $\Upsilon_{j}$ in the structural VECM. The result is a parsimonious structural vector equilibrium correction model denoted PSVECM, which is nested in (7) and defined by the selected $\boldsymbol{\delta}^{*}, \tilde{\boldsymbol{\alpha}}^{*}$ and $\boldsymbol{\Upsilon}_{j}^{*}$ with $j=1, \ldots, p-1$.

\section{The data}

The macroeconometric two-country model for the UK and the US we develop in this paper, consists of nine variables: inflation, output growth, 3-month interest rates, 10-year government bond yields for both countries, and the nominal exchange rate. We are using monthly data from $1972 M 3$ to $2010 M 8$ giving a total of 462 monthly observations. The paper is written from an UK perspective, so we will refer to UK variables as the domestic and US variables as foreign ones, marked by a star. Table 2 gives an overview over the macro time series under consideration.

To guarantee the consistency of the parity conditions to be considered the variables have been transformed to ensure that interest, inflation and growth rates are measured as monthly log returns. Table 3 explains in detail how each variable entering the model has been created. ${ }^{3}$

\footnotetext{
${ }^{3}$ A detailed discussion of relevant international parity conditions can be found in Heinlein and Krolzig (2012).
} 
Table 2 Time series definitions and source

\begin{tabular}{|c|c|c|c|}
\hline \multicolumn{2}{|c|}{ Variable Description } & \multirow{2}{*}{$\begin{array}{l}\text { Source } \\
\text { ONS }\end{array}$} & \multirow{2}{*}{$\begin{array}{l}\text { EcoWin code } \\
e w: g b r 11815\end{array}$} \\
\hline$P_{t}$ & $\begin{array}{l}\text { UK Retail Prices, all items excluding mortgage interest payments } \\
\text { (RPIX), Index, }(1987 \mathrm{M} 1=100) \text {, spliced with RPI (before 1975) }\end{array}$ & & \\
\hline$Y_{t}$ & UK Industrial Production, SA, $(2005=100)$, USD & IFS & ifs : $s 1126600 \mathrm{czfm}$ \\
\hline$I_{t}$ & UK Treasury bills, Bid, 3 month, Yield, End of Period, GBP & Reuters & ew : $g b r 14010$ \\
\hline$R_{t}$ & UK Government Benchmarks, Bid, 10 year, Yield, End of Period, GBP & Reuters & ew : $g b r 14020$ \\
\hline$P_{t}^{*}$ & US Consumer Prices, all items, SA, Index, (1982-1984=100) & BLS/Reuters & ew : usa 11970 \\
\hline$Y_{t}^{*}$ & US Industrial Production, SA, $(2005=100)$, USD & IFS & ifs : $s 1116600 \mathrm{czfm}$ \\
\hline$I_{t}^{*}$ & US Treasury bills, 3 month, Yield, Close, USD & Reuters & ew : usa 14430 \\
\hline$R_{t}^{*}$ & US Government Benchmarks, Bid, 10 Year, Yield, End of Period, USD & Reuters & ew : usa 14021 \\
\hline$e_{t}$ & Spot rates, GBP/USD transformed to USD/GBP, End of period & Reuters & ew : $g b r 19005$ \\
\hline
\end{tabular}

The price index $P_{t}$ is seasonally adjusted with Seats/Tramo. Both industrial production series $Y_{t}, Y_{t}^{*}$ are outlier corrected with Seats/Tramo. Variables without a superindex are of the domestic country (UK), a ${ }^{*}$ indicates the foreign country (US), ${ }^{a}$ is a country average and ${ }^{d}$ indicates a country difference. All financial variables are end-of-period series.

Table 3 Model variables

\begin{aligned} & \hline \hline \multicolumn{1}{c}{ Variable } Description \\ & \hline$\pi_{t}=\Delta \log P_{t}$ rate of inflation \\ &$\Delta y_{t}=\Delta \log Y_{t}$ output growth rate \\ &$i_{t}=\log \left(1+I_{t} / 1200\right)$ short-term interest rate \\ &$r_{t}=\log \left(1+R_{t} / 1200\right)$ long-term interest rate \\ &$e_{t}=\log E_{t}$ exchange rate \\ & \hline \hline\end{aligned}

The time series entering our model are plotted in Figure 1 displaying the time series of the rates of inflation, output growth, short- and long-term interest rates in the UK and the US as well as the exchange rate. Due to their relevance for the econometric modelling in $\$ 4$ we also show here the differences between the two countries and averages. As discussed above, the cointegration analysis will be performed separately for these 5D and 4D subsystems, before returning to the full 9D two-country model.

In the Appendix A, we briefly discuss the properties of the macro time series as far as relevant for the econometric modelling in $\S 4$ and $\S 5$. We focus here particulary on the international parity conditions that constitute strong candidates for the cointegration relations.

\section{The long-run - an application of the Aoki method}

In the following, we will assume symmetry in the long-run but allow for country-specific contemporaneous effects, short-run dynamics and speeds of adjustment. ${ }^{4}$ Long-run symmetry invokes the approach of Aoki (1981) for the analysis of the cointegration properties of the system. Separating the 9D dynamics into two autonomous subsystems makes the likelihood based cointegration analysis of the two-country model feasible.

For the cointegration analysis, the variables of the model are transformed from domestic-foreign into country-average-difference measures. The exchange rate is included in the country-difference system. Thus, the cointegration analysis is performed in a country difference model of dimension 5 and the

\footnotetext{
${ }^{4}$ This long-run symmetry assumption will be tested in Chapter 4.3 and cannot be rejected. To further scrutinise the assumption, we analyse a PSVECM(3) with an unrestricted long-run. The dynamics of the baseline model are much more reasonable than those of the long-run-unrestricted alternative. The conclusion of the paper in respect to the overshooting effect of the exchange rate is not driven by wrongly imposed restrictions on the cointegration space due to the symmetry assumption. Results for this robustness check can be requested from the authors.
} 

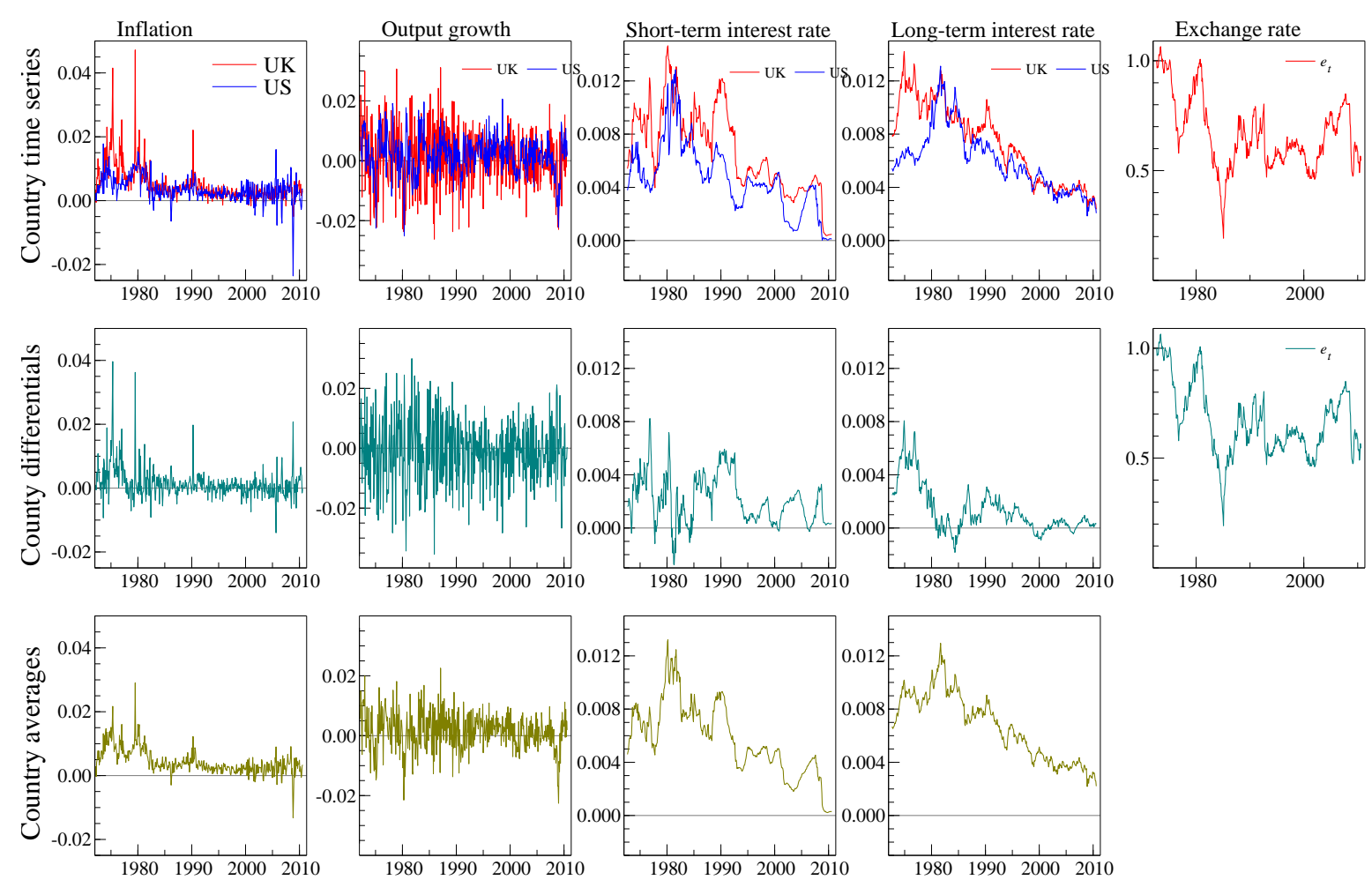

Figure 1 Time series. The top row displays the untransformed series for the US and UK, followed by the plots of corresponding country-differences and country-averages.

country average model of dimension 4 , see chapters 4.1 and 4.2 respectively. Subsequently the variables will be transformed back into the original system with the error correction terms preserved and the short-run being analysed in the full 9-dimensional system.

\subsection{Cointegration in the country difference subsystem}

The analysis of the country difference subsystem can be build upon the results of Heinlein and Krolzig (2012), who analyzed a 5D country difference model for the UK and the US using quarterly data from 1972Q1 to 2009Q2. They identified the following cointegration relations:

(i) Stationary output growth differential: $\Delta y_{t}^{d}=\Delta y_{t}-\Delta y_{t}^{*} \sim I(0)$.

(ii) Stationary nominal short-term interest rate differential: $i^{d}=i_{t}-i_{t}^{*} \sim I(0)$.

(iii) Stationary real long-term interest rate differential: $\rho_{t}^{d}=(r-\pi)_{t}-\left(r^{*}-\pi^{*}\right)_{t} \sim I(0)$.

(iv) Long-term interest-rate differential based exchange rate determination: $e_{t}-\beta\left(r-r^{*}\right)_{t} \sim I(0)$.

The last cointegration vector is a UIP inspired exchange rate determination relation, which Heinlein and Krolzig (2012) propose to interpret in light of the multi-period form of UIP: Generalizing (25) to zero bonds with multi-period maturities in line with the EHT, we have that the long-term interest rate equalizes the expected average return of one-period bonds over $T$ periods:

$$
r_{t}^{d}=\frac{1}{T} \sum_{j=0}^{T-1} \mathrm{E}_{t} i_{t+j}^{d} .
$$


Combining (8) with the forward solution of the UIP relation in (25) for $e_{t}$,

$$
e_{t}=\mathrm{E}_{t} e_{t+T}+\sum_{j=0}^{T-1} \mathrm{E}_{t} i_{t+j}^{d},
$$

a multi-period form of UIP is gained as:

$$
e_{t}=\mathrm{E}_{t} e_{t+T}+T\left(r-r^{*}\right)_{t}
$$

Hence, the exchange rate is determined by the long-term exchange rate expectation, $\mathrm{E}_{t} e_{t+T}$, and $T$ times the long-term interest rate differential. For zero bonds with a maturity of 10 years, respectively $T=120$ months, this results in:

$$
e_{t}=\mathrm{E}_{t} e_{t+120}+120 r_{t}^{d}
$$

In other words, we expect that $\beta \approx 120$ in our case.

In order to identify the cointegration vectors for the data considered here, we commence by developing a congruent statistical model for the macro dynamics of the country differences involving the inflation differential, $\pi_{t}^{d}=\pi_{t}-\pi_{t}^{*}$, the output growth differential, $\Delta y_{t}^{d}=\Delta y_{t}-\Delta y_{t}^{*}$, the short-term interest rate differential, $i_{t}^{d}=i_{t}-i_{t}^{*}$, the long-term interest rate differential, $r_{t}^{d}=r_{t}-r_{t}^{*}$, and the exchange rate $e_{t}$. The results of Augmented Dickey Fuller tests indicate that the output growth differential $\Delta y_{t}^{d}$ is stationary and the short-term interest rate differential $i_{t}^{d}$ is marginally stationary. The other time series were found to be $I(1)$. Thus, the vector process, $\tilde{\boldsymbol{x}}_{t}^{d}=\left(\pi_{t}^{d}, \Delta y_{t}^{d}, i_{t}^{d}, r_{t}^{d}, e_{t}\right)^{\prime}$ is integrated of order one: $\tilde{\boldsymbol{x}}_{t}^{d} \sim I(1)$.

As discussed in \$2.1, the first step involves the specification of the deterministic terms, selection of the lag length and misspecification tests to check the validity of the assumptions made. An unrestricted constant is included in the model. It is the only deterministic term as a linear time trend was found to be statistically insignificant. The lag structure analysis of the unrestricted VAR, commencing from a maximum lag length of thirteen with consecutive F-tests for excluded individual and joint lags, indicated a lag order of four. ${ }^{5}$ Most importantly, non of the equations suffers from autocorrelation. As one would expect in financial time series data non-normality and heteroscedasticity are detected.

We continue by analyzing the long-run properties of the system. The number of stable long-run relations $\boldsymbol{\beta}^{\prime} \tilde{\boldsymbol{x}}_{t}^{d}$, which is equal to the rank of the matrix $\boldsymbol{\Pi}$ of the vector equilibrium-correction mechanism in (4), is determined by the Johansen (1995) test for $I(1)$ cointegration. The eigenvalues and trace test results are shown in Table 4. The long-run properties of the system are characterized by four cointegration relations, $\operatorname{rank}(\boldsymbol{\Pi})=4$, and one stochastic trend.

Table 4 Johansen likelihood ratio trace test of $H_{0}:$ rank $\leq r$

\begin{tabular}{cccc}
\hline \hline$r$ & eigenvalue & trace test & prob \\
\hline 0 & 0.263 & $274.60^{* *}$ & {$[0.000]$} \\
1 & 0.189 & $133.48^{* *}$ & {$[0.000]$} \\
2 & 0.042 & $36.73^{* *}$ & {$[0.006]$} \\
3 & 0.030 & $16.69^{*}$ & {$[0.031]$} \\
4 & 0.005 & 2.48 & {$[0.115]$} \\
\hline \hline \multicolumn{4}{c}{ significant at 1\% level, ${ }^{*}$ significant at 5\% level. }
\end{tabular}

\footnotetext{
${ }^{5}$ The results of tests for misspecification are displayed in Table 10 in Appendix $B$.
} 
We test for long-run weak exogeneity of the variables of the system. Under the null hypothesis of a particular zero row in $\alpha$, the corresponding variable is not adjusting towards the long-run equilibrium. The LR test results of the restrictions on $\boldsymbol{\alpha}$ show that, with a p-value of 0.72 , the bond yield differential is the only weakly exogenous variable. Thus, we identified the long-term interest rate differential $r_{t}^{d}$ as the unique common stochastic trend in the system, see Table 11 in Appendix $B .^{6}$

Following the modelling approach suggested by Juselius (2006), the following cointegration vectors were identified by paying attention not only to statistical acceptability but also to consistency with economic theory. Three linearly independent cointegration vectors related to parity conditions (i) to (iii) were found by means of simple hypothesis tests. With $\operatorname{rank}^{d}=4$, one further composite cointegration vector had to be identified as (iv).

(i) Stationary output growth differential.

$$
\Delta y_{t}^{d}=\Delta y_{t}-\Delta y_{t}^{*} \sim I(0) .
$$

The first cointegration vector is the difference between the UK and US output growth rates, which follows from the stationarity of the output growth rates of both countries.

(ii) Stationary nominal short-term interest rate differential.

$$
i^{d}=i_{t}-i_{t}^{*} \sim I(0)
$$

This is somewhat surprising given that the long-term interest rate differential constitutes the stochastic trend of the system. In other words, while the nominal interest rate parity holds for the money markets, it is violated for the bond markets.

The opposite holds for the real interest rate parity:

(iii) Stationary real long-term interest rate differential.

$$
\rho_{t}^{d}=r_{t}^{d}-\pi_{t}^{d}=(r-\pi)_{t}-\left(r^{*}-\pi^{*}\right)_{t} \sim I(0) .
$$

The third cointegrating vector reflects the real interest rate parity and is closely related to the Fisher hypothesis, where the real long-term interest rates are calculated naively with the current rather than the expected future inflation. Since $r_{t}^{d}$ is nonstationary this must also hold for the inflation differential, which is driven by the same stochastic trend. It is also worth noting that due to (13) and (14) the UK and US term structures do not cointegrate.

(iv) Nominal long-term interest-rate differential based exchange rate determination.

$$
e_{t}-\beta\left(r-r^{*}\right)_{t} \sim I(0)
$$

\footnotetext{
${ }^{6}$ In the following, we will see that the long-term interest rate differential appears to be driven by long-term inflation expectations as predicted in Fisher hypothesis.
} 
While, for the type of government bonds analyzed here, the relation in (11) the estimated multiplier of $\hat{\beta}=87.2$ with a $2 \sigma$ interval of $[43.10,131.33]$ is consistent with the theory. Furthermore, with sample averages of 8.9 and 7.3 of the yield of 10 -year government bonds of the UK and the US, the average duration is only 6.8 and 7.3 years, respectively. Thus, the point estimate of 87.2 is actually very close to the predicted values of 81.6 and 87.6. According to (11), the longterm equilibrium movement in the foreign exchange rate can be traced back to the non-stationary nominal long-term interest rate differential, exhibiting long swings, and long-term exchange rate expectations.

The system estimation results for the four cointegration vectors and their interaction with the variables of the system are shown in Table 12 in Appendix $B$. The three over-identifying restrictions on the cointegration space are accepted by the likelihood ratio (LR) test with a statistic of $\chi^{2}(3)=3.67$ and a p-value of 0.30 . The only unrestricted $\boldsymbol{\beta}$-coefficient is precisely estimated. In contrast, only few $\alpha$-coefficients are statistically different from zero. The four cointegrating relations can be seen in the upper panels of Figure 2.

Altogether we find that the nominal long-term interest rate differential, $r_{t}^{d}$, is of central importance to the system. It constitutes the common stochastic trend, it cointegrates with the inflation differential $\pi_{t}^{d}$ to the stationary 'real' long-term rate differential, and it also drives the exchange rate $e_{t}=87.2 r_{t}^{d}$, which is consistent with UIP and stable long-term exchange rate expectations $\mathrm{E}_{t} e_{t+120}$. The output gap $y_{t}^{d}$ and the short-term rate differential $i_{t}^{d}$ are both self error correcting and weakly exogenous to the other cointegration relations.

Overall, it is very reassuring that the same long-run cointegration relationships could be found for both studies, earlier with quarterly data and now with monthly data.

\subsection{Cointegration in the country average subsystem}

The country average subsystem is a four dimensional model containing the inflation average, $\pi_{t}^{a}=$ $0.5\left(\pi_{t}+\pi_{t}^{*}\right)$, the output growth average, $\Delta y_{t}^{a}=0.5\left(\Delta y_{t}+\Delta y_{t}^{*}\right)$, the short-term interest rate average, $i_{t}^{a}=0.5\left(i_{t}+i_{t}^{*}\right)$ and the long-term interest rate average, $r_{t}^{a}=0.5\left(r_{t}+r_{t}^{*}\right)$. The results of Augmented Dickey Fuller tests indicate that the output growth average $\Delta y_{t}^{a}$ is stationary, the inflation average $\pi_{t}^{a}$ is trend stationary, also the interest rate averages are close to be marginally trend stationary. Altogether the vector process, $\tilde{\boldsymbol{x}}_{t}^{a}=\left(\pi_{t}^{a}, \Delta y_{t}^{a}, i_{t}^{a}, r_{t}^{a}\right)^{\prime}$ is integrated of order one: $\tilde{\boldsymbol{x}}_{t}^{a} \sim I(1)$.

Again we start with the specification of the deterministic terms, selection of the lag length and misspecification test to check the validity of the assumptions made. The lag structure analysis of the unrestricted VAR, indicates a lag order of three. An unrestricted constant is included as deterministic term. A linear trend is statistically significant but excluded on economic grounds. When the trend is included, the average inflation as well as the long-term interest rate are stationary cointegration relationships on its own. This deterministic downward trend is a pure sample effect and not supported by economic theory.

The results of tests for misspecification are displayed in Table 13 in Appendix $B$. The autocorrelation test with 13 lags is a demanding test to pass. Therefore we are content with a $1 \%$ significance level, which is passed in all equations but the inflation rate equation. The UK price index, which is provided by the Office for National Statistics (ONS) seasonally unadjusted, has been seasonally adjusted using 

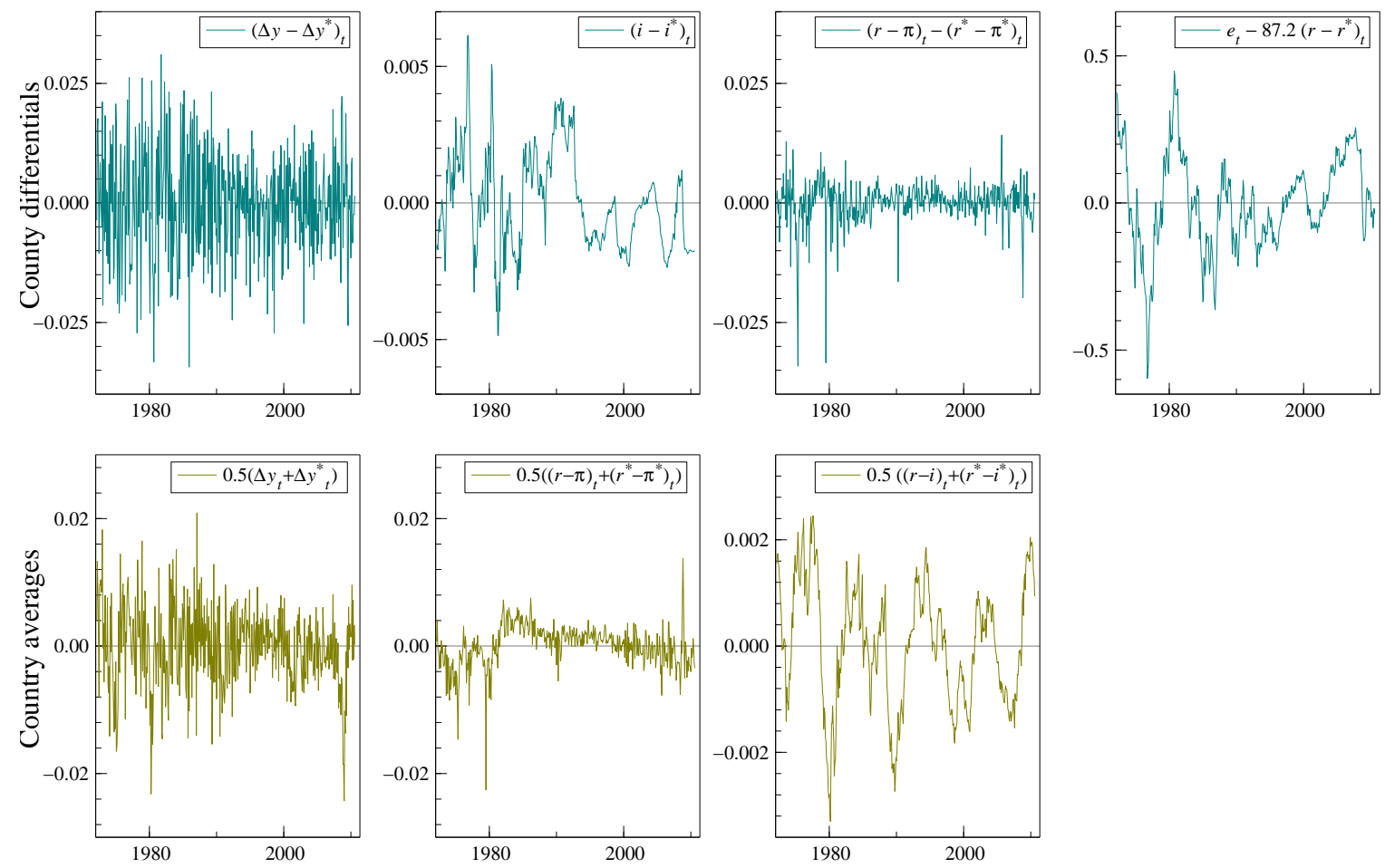

Figure 2 The seven cointegrating vectors of the country-difference and country-average subsystems.

the programme TRAMO/SEATS. Despite the seasonal adjustment residual autocorrelation is present in the inflation rate equation.

We continue by analyzing the long-run properties of the country average system. Like before, the number of stable long-run relations $\boldsymbol{\beta}^{\prime} \tilde{\boldsymbol{x}}_{t}^{a}$, is determined by the Johansen (1995) test for $I(1)$ cointegration. The eigenvalues and trace test results for the model with an unrestricted constant are shown in Table 5. According to this result the rank of the matrix $\Pi$ is two. The constant is in the unrestricted model, not only jointly with a F-test p-val of 0.82 , but also in every equation, highly insignificant. The trace test results for a model without a constant, see Table 6, suggest a rank of three. The critical cointegration relationship, which would drop out of the three cointegration relations we present in the following if we restrict the rank to two, is the term spread relation. The term spread is a very important economic relation. Therefore for economic reasons we decide here to go with a rank of three in the country-average model. So the long-run properties of the system are characterized by three cointegration relations and one common stochastic trend.

Table 5 Johansen likelihood ratio trace test of $H_{0}:$ rank $\leq r$. Model including a constant

\begin{tabular}{cccc}
\hline \hline$r$ & eigenvalue & trace test & prob \\
\hline 0 & 0.184 & $149.23^{* *}$ & {$[0.000]$} \\
1 & 0.088 & $55.25^{* *}$ & {$[0.000]$} \\
2 & 0.026 & 12.61 & {$[0.131]$} \\
3 & 0.001 & 0.65 & {$[0.420]$} \\
\hline \hline
\end{tabular}


Table 6 Johansen likelihood ratio trace test of $H_{0}$ : rank $\leq r$. Model without constant

\begin{tabular}{cccc}
\hline \hline$r$ & eigenvalue & trace test & prob \\
\hline 0 & 0.184 & $148.04^{* *}$ & {$[0.000]$} \\
1 & 0.087 & $54.10^{* *}$ & {$[0.000]$} \\
2 & 0.024 & 11.91 & {$[0.058]$} \\
3 & 0.001 & 0.57 & {$[0.517]$} \\
\hline \hline
\end{tabular}

The likelihood ratio test results for long-run weak exogeneity indicate that the short-term interest rate average and the long-term interest rate average are candidates for the common stochastic trend, see Table 14 in Appendix $B$.

A clear idea of the cointegration relationships can be drawn from tests of simple hypotheses. A combination of the three cointegration relationships is not only statistically accepted but economically reasonable.

(i) Stationary output growth average.

$$
\Delta y_{t}^{a}=0.5\left(\Delta y_{t}+\Delta y_{t}^{*}\right) \sim I(0) .
$$

The first cointegration vector is the average between the UK and US output growth rates. Stationarity is expected here due to the stationarity of the output growth rates of both countries.

(ii) Stationary real long-term interest rate average.

$$
r_{t}^{a}-\pi_{t}^{a}=0.5\left[(r-\pi)_{t}+\left(r^{*}-\pi^{*}\right)_{t}\right] \sim I(0) .
$$

The second cointegration vector is the average between the UK and the US real long-term interest rates. The Fisher relation suggests the stationarity of the real rates, a country average of real rates is even more likely stationary.

(iii) Stationary term spread average.

$$
r_{t}^{a}-i_{t}^{a}=0.5\left[(r-i)_{t}+\left(r^{*}-i^{*}\right)_{t}\right] \sim I(0) .
$$

The third cointegrating vector reflects the stationarity of the spread between long and short-term interest rate averages.

The system estimation results for the three cointegration vectors, see their plot in the lower panels of Figure 2, and their interaction with the variables of the system are shown in Table 15 in Appendix $B$. The three over-identifying restrictions on the cointegration space are accepted by a likelihood ratio (LR) test with a statistic of $\chi^{2}(3)=1.54$ and a p-value of 0.67 . All $\boldsymbol{\beta}$-coefficients are restricted. Only some $\boldsymbol{\alpha}$-coefficients are statistically different from zero. ${ }^{7}$

\footnotetext{
${ }^{7}$ The long-term real interest rate average is chosen in the second cointegration relationship instead of the short-term real rate
} 
Because both interest rate averages are marginally adjusting to cointegration relationships, it is not obvious what is the common stochastic trend. In the moving average representation of the model, a normalized version of the orthogonal complement of the matrix beta, $\boldsymbol{\beta}_{\perp}^{a}$, is the loading to the common stochastic trend and $\boldsymbol{\alpha}_{\perp}^{a^{\prime}} \sum_{i=1}^{t} \boldsymbol{u}_{i}^{a}$ is the common driving trend, with $\boldsymbol{u}_{t}^{a}$ being the residuals of the system, see Johansen (1995). The matrix $\boldsymbol{\alpha}_{\perp}^{a}$ is defined by $\boldsymbol{\alpha}^{a^{\prime}} \boldsymbol{\alpha}_{\perp}^{a}=\mathbf{0}$ and looks as follows:

$$
\boldsymbol{\alpha}^{a^{\prime}}=\left(\begin{array}{rrrr}
-0.022 & -0.619 & 0.008 & 0.002 \\
0.251 & 0.136 & -0.006 & -0.009 \\
-0.055 & 0.838 & 0.023 & -0.011
\end{array}\right) \quad \text { and } \quad \boldsymbol{\alpha}_{\perp}^{a}=\left(\begin{array}{l}
0.037 \\
0.006 \\
0.340 \\
0.940
\end{array}\right)
$$

Thus the common stochastic trend of the country average model, $C S T^{a}$, is a linear combination of the cumulated prediction errors of the long-term interest rate and the short-term interest rate equations. Overall the stochastic trend is very similar to the country average of the bond rates with a correlation of 0.94, see Figure 3 middle panel. The bond rates are pushing the system.

\subsection{Testing for long-run symmetry}

When deriving the cointegration vectors of the two-country model, we assumed symmetry of the UK and the US economy. To confirm this assumption we analyse the degree of separation in the cointegrated system following Konishi et al. (1993), Gonzalo and Granger (1995) and Granger and Haldrup (1997). Long-run separation is equivalent to long-run symmetry in our set-up. Only when the stochastic trends of the two subsystems do not cointegrate there exist no cointegration relationships combining variables of both subsystems. As we have seen, the two detected stochastic trends are similar to the long-term interest rate differential, $r_{t}^{d}$, of the country difference subsystem and to the long-term interest rate average, $r_{t}^{a}$, of the country average subsystem, see Figure 3. A trace test for a system consisting of the two stochastic trends clearly does not reject a zero rank with a trace test p-value of $0.37 .^{8}$ Since the two stochastic trends do not cointegrate the separate analysis of the long-run is appropriate.

\section{The full two-country macro dynamics}

\subsection{Testing for short-run symmetry}

After having analysed the long-run we now focus on the contemporaneous effects and the short-run dynamics. Is the symmetry assumption also acceptable for the short-run? If yes, the country average and the country difference vector space are orthogonal to each other. Regressors from the country average system would not be significant, when regressed on country difference variables, and the other

because of the following reasons. Due to the term spread cointegration relationship both options are equivalent in a way that they are two different representations of the same model with exactly the same likelihood. But in the following econometric modelling procedure the further restricting of the model leads to different selected parsimonious models for the two options and thus different final models. The decision is made upon the better Akaike and Schwarz information criteria of the final 9dimensional model, which are both in favour of the model option with the second cointegration relationship to be the stationary long-term real interest rate average.

${ }^{8}$ In the bivariate system of the two stochastic trends, no deterministic trend is included. As in the country average subsystem the country average bond rate would be marginally accepted as a cointegration relationship and loose the property of a stochastic trend, i.e. the country average system would become trend-stationary. 


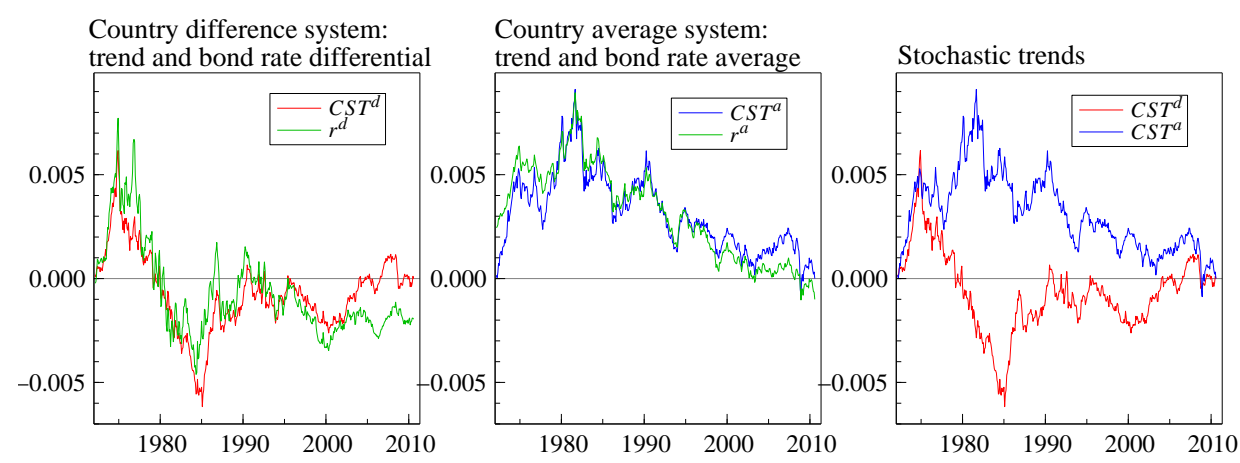

Figure 3 Stochastic trends of the country difference and country average subsystems

way around. Thus symmetry can be tested with overidentifying restrictions. In the combined averagedifference VECM, see (19), short-run symmetry is tested by testing for significance of the off-diagonal block coefficient matrices.

$$
\begin{aligned}
{\left[\begin{array}{c}
\Delta \tilde{\boldsymbol{x}}_{t}^{a} \\
\Delta \tilde{\boldsymbol{x}}_{t}^{d}
\end{array}\right]=} & {\left[\begin{array}{l}
\boldsymbol{\nu}_{a} \\
\boldsymbol{\nu}_{d}
\end{array}\right]+\left[\begin{array}{ll}
\boldsymbol{\alpha}_{a a} & \boldsymbol{\alpha}_{a d} \\
\boldsymbol{\alpha}_{d a} & \boldsymbol{\alpha}_{d d}
\end{array}\right]\left[\begin{array}{c}
\boldsymbol{\beta}_{a}^{\prime} \tilde{\boldsymbol{x}}_{t-1}^{a} \\
\boldsymbol{\beta}_{d}^{\prime} \tilde{\boldsymbol{x}}_{t-1}^{d}
\end{array}\right] } \\
& +\left[\begin{array}{ll}
\boldsymbol{\Gamma}_{a a, 1} & \boldsymbol{\Gamma}_{a d, 1} \\
\boldsymbol{\Gamma}_{d a, 1} & \boldsymbol{\Gamma}_{d d, 1}
\end{array}\right]\left[\begin{array}{c}
\Delta \tilde{\boldsymbol{x}}_{t-1}^{a} \\
\Delta \tilde{\boldsymbol{x}}_{t-1}^{d}
\end{array}\right]+\left[\begin{array}{ll}
\boldsymbol{\Gamma}_{a a, 2} & \boldsymbol{\Gamma}_{a d, 2} \\
\boldsymbol{\Gamma}_{d a, 2} & \boldsymbol{\Gamma}_{d d, 2}
\end{array}\right]\left[\begin{array}{c}
\Delta \tilde{\boldsymbol{x}}_{t-2}^{a} \\
\Delta \tilde{\boldsymbol{x}}_{t-2}^{d}
\end{array}\right] \\
& +\left[\begin{array}{ll}
\mathbf{0} & \boldsymbol{\Gamma}_{a d, 3} \\
\mathbf{0} & \boldsymbol{\Gamma}_{d d, 3}
\end{array}\right]\left[\begin{array}{c}
\mathbf{0} \\
\Delta \tilde{\boldsymbol{x}}_{t-3}^{d}
\end{array}\right]+\left[\begin{array}{c}
\boldsymbol{u}_{t}^{a} \\
\boldsymbol{u}_{t}^{d}
\end{array}\right], \\
& \text { where }\left[\begin{array}{c}
\boldsymbol{u}_{t}^{a} \\
\boldsymbol{u}_{t}^{d}
\end{array}\right] \sim \operatorname{NID}\left(\left[\begin{array}{l}
\mathbf{0} \\
\mathbf{0}
\end{array}\right],\left[\begin{array}{ll}
\boldsymbol{\Sigma}^{a a} & \boldsymbol{\Sigma}^{a d} \\
\boldsymbol{\Sigma}^{d a} & \boldsymbol{\Sigma}^{d d}
\end{array}\right]\right) .
\end{aligned}
$$

In table 7, tests of Hypotheses $\mathrm{H}_{1}$ and $\mathrm{H}_{2}$ show that the country average cointegration relationships have explanatory power in the country difference equation and vice versa. From this it can be followed that the adjustment processes are different in the two countries. Hypotheses $\mathrm{H}_{3}$ and $\mathrm{H}_{4}$ are concerned with the significance of the off-diagonal short-run dynamics. The short-run dynamics of the country average subsystem have marginally explanatory power in the country difference equations, but the shortrun dynamics of the country difference model is clearly not helpful in explaining the country average variables. The rejection of Hypotheses $\mathrm{H}_{5}$ and $\mathrm{H}_{6}$ show that the adjustment coefficients jointly with the short-run dynamics of one subsystem do have explanatory power in the other subsystem. Symmetry in the short-run and in the adjustment to the long-run is clearly rejected. For the following analysis we return to the full model of domestic-foreign variables with the cointegration relationships found in $\S 4.1$ and $\$ 4.2$ preserved.

\subsection{Identifying instantaneous causality}

The residual correlation matrix of the full 9-dimensional $\operatorname{VECM}(3)$ with the cointegration relationships identified before is reported in Table 8. Clear statistically significant contemporaneous correlation of 
Table 7 Testing overidentifying restrictions for short-run and long-run country symmetry

\begin{tabular}{lll}
\hline \hline$H_{o}^{1}: \boldsymbol{\alpha}_{d a}=0$ & $\chi^{2}(15)=27.2$ & {$[0.027]$} \\
$H_{o}^{2}: \boldsymbol{\alpha}_{a d}=0$ & $\chi^{2}(16)=47.7$ & {$[0.000]$} \\
$H_{o}^{3}: \Gamma_{d a, 1}=0, \Gamma_{d a, 2}=0$ & $\chi^{2}(40)=55.3$ & {$[0.055]$} \\
$H_{o}^{4}: \Gamma_{a d, 1}=0, \Gamma_{a d, 2}=0, \Gamma_{a d, 3}=0$ & $\chi^{2}(60)=72.4$ & {$[0.130]$} \\
$H_{o}^{5}: \boldsymbol{\alpha}_{d a}=0, \Gamma_{d a, j}=0$ & $\chi^{2}(55)=90.4$ & {$[0.002]$} \\
$H_{o}^{6}: \boldsymbol{\alpha}_{a d}=0, \Gamma_{a d, j}=0$ & $\chi^{2}(76)=134.8$ & {$[0.000]$} \\
\hline \hline
\end{tabular}

shocks is between the short and long-term interest rates of each country. Thus, in the very short term, the term spread is a strong link between the macroeconomic variables. As the dominant force in transmitting and absorbing macroeconomic shocks, it will play an important role in the transmission of monetary shocks to the exchange rate. Another large contemporaneous correlation of shocks is between the domestic and foreign bond yields, due to the strong interconnectedness of financial markets. Only weak correlation is present relative to the exchange rate, see last row of Table 8, what is of interest when studying the impact effects of monetary policy on exchange rates.

Table 8 Contemporaneous correlation of the VECM

\begin{tabular}{l|rrrr|rrrr|r}
\hline \hline & $\pi_{t}$ & $\Delta y_{t}$ & $i_{t}$ & $r_{t}$ & $\pi_{t}^{*}$ & $\Delta y_{t}^{*}$ & $i_{t}^{*}$ & $r_{t}^{*}$ & $e_{t}$ \\
\hline$\pi_{t}$ & 1 & & & & & & & & \\
$\Delta y_{t}$ & -0.02 & 1 & & & & & & & \\
$i_{t}$ & 0.00 & 0.07 & 1 & & & & & & \\
$r_{t}$ & 0.08 & 0.03 & $\mathbf{0 . 5 2}$ & 1 & & & & & \\
\hline$\pi_{t}^{*}$ & 0.13 & -0.06 & 0.15 & 0.10 & 1 & & & & \\
$\Delta y_{t}^{*}$ & 0.01 & 0.06 & 0.02 & 0.06 & 0.05 & 1 & & & \\
$i_{t}^{*}$ & -0.02 & -0.04 & 0.13 & 0.22 & 0.10 & 0.19 & 1 & & \\
$r_{t}^{*}$ & 0.04 & 0.01 & 0.12 & $\mathbf{0 . 3 8}$ & 0.17 & 0.17 & $\mathbf{0 . 5 4}$ & 1 & \\
\hline$e_{t}$ & 0.05 & -0.05 & -0.09 & -0.10 & 0.12 & -0.06 & -0.14 & -0.15 & 1 \\
\hline \hline
\end{tabular}

For further investigations of these issues, the correlation matrix in Table 8 is subjected to a graphtheoretical search for instantaneous causal relations. The Conservative PC algorithm (CPC) is applied in the following, which is a variant of the $\mathrm{PC}$ algorithm, designed to improve arrowpoint orientation accuracy. The CPC algorithm finds, at a $10 \%$ significance level ${ }^{9}$ four directed and five undirected edges. To orthogonalise the variance-covariance matrix and pass the tests to have all contemporaneous effects considered, we iterate on using the CPC algorithm and find an additional undirected edge in the causal structure, connecting the US short-term interest rate and the exchange rate. The exchange rate is not significant in the US interest rate equation, with p-values between 0.13 to 0.91 depending on specification of this equation, while the US short term interest rate is highly significant in the exchange rate equation. By the inclusion of this link the number of models increase to 48 . We select a best model via information criteria. ${ }^{10}$ The variance-covariance matrix is now orthogonal. The LR test with a test statistic of $\chi^{2}(26)=31.13$ and a p-value of 0.22 does not reject the hypothesis of a diagonal covariance matrix. After directing all six undirected edges the causal structure is fully determined like shown in Figure 4.

\footnotetext{
${ }^{9}$ Because of the importance of the causal structure for the issue of an impact effect on the exchange rate and hence the question of the delayed overshooting, we decide to go here with a $10 \%$ significance level.

${ }^{10}$ The interested reader can find details in the working paper version of this paper.
} 


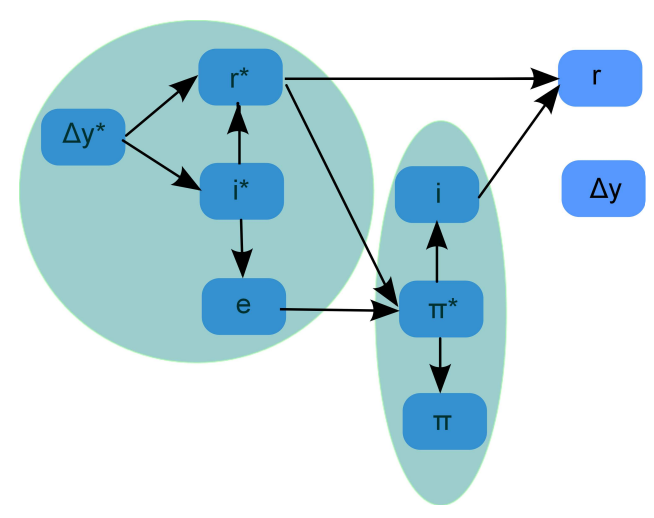

Figure 4 Final causal structure

The identified causal structure is mapped into the contemporaneous matrix ${ }^{11} \mathbf{B}^{r}$, see Table 9. Compared to a Cholesky decomposition our causal structure is highly parsimonious. Only a few non-zero lower-off-diagonal elements are present. There are two blocks in this contemporaneous matrix, one is the set of US variables together with the exchange rate, the other block is the set of UK variables. This block-recursive structure shows that in the very short-run the UK can be described by a small economy model. The interest rates are ordered before the inflation rates, what might be explained by the monetary policy authorities having to rely on historical databased nowcasts for policy making. The exchange rate being ordered after the US short-term interest rate but before the UK short-term interest rate implies a 'delayed' response of the exchange rate after a monetary policy action of the Bank of England.

Table 9 Final design of the restricted $\boldsymbol{B}^{r}$ matrix

$$
\begin{gathered}
\Delta y_{t}^{*} \\
i_{t}^{*} \\
r_{t}^{*} \\
e_{t} \\
\pi_{t}^{*} \\
\Delta y_{t} \\
i_{t} \\
r_{t} \\
\pi_{t}
\end{gathered} \quad\left(\begin{array}{ccccccccccc}
1 & & & & & & & & & \\
b_{21} & 1 & & & & & & & \\
b_{31} & b_{32} & 1 & & & & & & \\
0 & b_{42} & 0 & 1 & & & & & \\
0 & 0 & b_{53} & b_{54} & 1 & & & & \\
0 & 0 & 0 & 0 & 0 & 1 & & & \\
0 & 0 & 0 & 0 & b_{75} & 0 & 1 & & \\
0 & 0 & 0 & 0 & 0 & 0 & b_{95} & 0 & 0 & 0 & 1
\end{array}\right)
$$

\subsection{The parsimonious structural vector equilibrium correction model}

Having specified the SVECM in (7) with the cointegration relations found in $\$ 4.1$ and $\$ 4.2$ and the contemporaneous relations detected by the empirical PC causal search algorithm in §5.2, the model reduction is performed with the help of an automatic general-to-specific model reduction procedure. As the design of $\boldsymbol{B}^{r}$ and the parameters of $\boldsymbol{\beta}^{s, r}$ are given, the model search is limited to the parameters of the short-run dynamics, $\Gamma_{1}, \ldots, \Gamma_{3}$, and the long-run equilibrium adjustment, $\boldsymbol{\alpha}$, while it is ensured that the rank of the long-run matrix $\Pi$ is unaltered by the constraints on $\boldsymbol{\alpha}$. As shown in Krolzig (2003),

\footnotetext{
${ }^{11}$ The presented causal order is not unique. The choice of one of the possible causal orderings does not influence the further analysis.
} 
when commencing from a structural VECM with known causal order and diagonal variance-covariance matrix, all possible reductions of the SVECM can be efficiently estimated by OLS and model selection procedures can operate equation-by-equation without a loss in efficiency. The liberal strategy of PcGets used here approximates in large samples the Hannan-Quinn (HQ) information criteria (for more about mapping information criteria to significance levels see Campos et al., 2003). The properties of automatic Gets selection are discussed in more detail in Hendry and Krolzig (2005).

The final parsimonious baseline model selected by PcGets and estimated with OLS is as follows: All coefficients are significant with a t-value of at least 2 . The adjusted $R^{2}$ of the reduced single equations are from $27 \%$ for the exchange rate equation up to $70 \%$ for the UK inflation rate equation. Major outliers are corrected by including impulse dummies. Only the exchange rate equation is reported here:

$$
\begin{aligned}
& \widehat{\Delta e}_{t}=1.97\left(i-i^{*}\right)_{t-1}+0.755\left[(r-\pi)_{t-1}-\left(r^{*}-\pi^{*}\right)_{t-1}\right] \\
& \text { (0.57) (0.27) } \\
& -0.0118\left[e_{t-1}-87.2\left(r-r^{*}\right)_{t-1}\right]+5.54 \Delta i_{t-3}-8.79 \Delta i_{t}^{*} \\
& (0.0032) \\
& \text { (2.4) } \\
& +9.56 \Delta r_{t-3}^{*}, \quad \hat{\sigma}=0.0255, \bar{R}^{2}=0.27,8 \text { dummies. }
\end{aligned}
$$

The exchange rate is error correcting towards three cointegration relationships. The first two can be interpreted as a carry trade effect, high rates lead to capital inflow, hence appreciation of the currency. The third is a multi-period UIP relation. Three cointegration relationships are driving the exchange rate, with all being from the country difference system. The importance of the cointegration approach is obvious. A lot of information would have been lost if the VAR had been specified in differences. Further, one contemporaneous effect is present in this equation. An increase of the short-term interest rate in the US leads to an appreciation of the dollar on impact.

\section{The effects of monetary policy shocks}

In this section, we consider the dynamic responses to an asymmetric monetary policy shock in form of an unpredicted one percentage-point increase of the nominal short-term interest rate of the UK and respectively of the US.

\subsection{An impulse response analysis of a monetary policy shock in the UK}

Figure 5 displays the responses of the system variables, i.e., the inflation rates, the output growth rates, the 3-month interest rates, the 10-year government bond yields, and the nominal exchange rate, with regard to an one-percentage point increase in the monthly 3-month treasury bill return of the UK. The 95\% confidence bands are Hall (1992) bootstrap intervals with 2000 replications. The computation follows the algorithm of Benkwitz et al. (2001) in the version without reestimation of the cointegration relations. Due to the employed model selection strategy, the impulse responses are estimated precisely offering clear conclusions about the sign of responses.

After a UK monetary policy shock the bond rate of the UK reacts contemporaneously with $31 \%$ of the size of the shock. Both UK interest rates slowly revert to the original level. The interest rates of the US increase, not on impact but steadily, to a peak of $40 \%$ of the size of the shock after 4 years for 

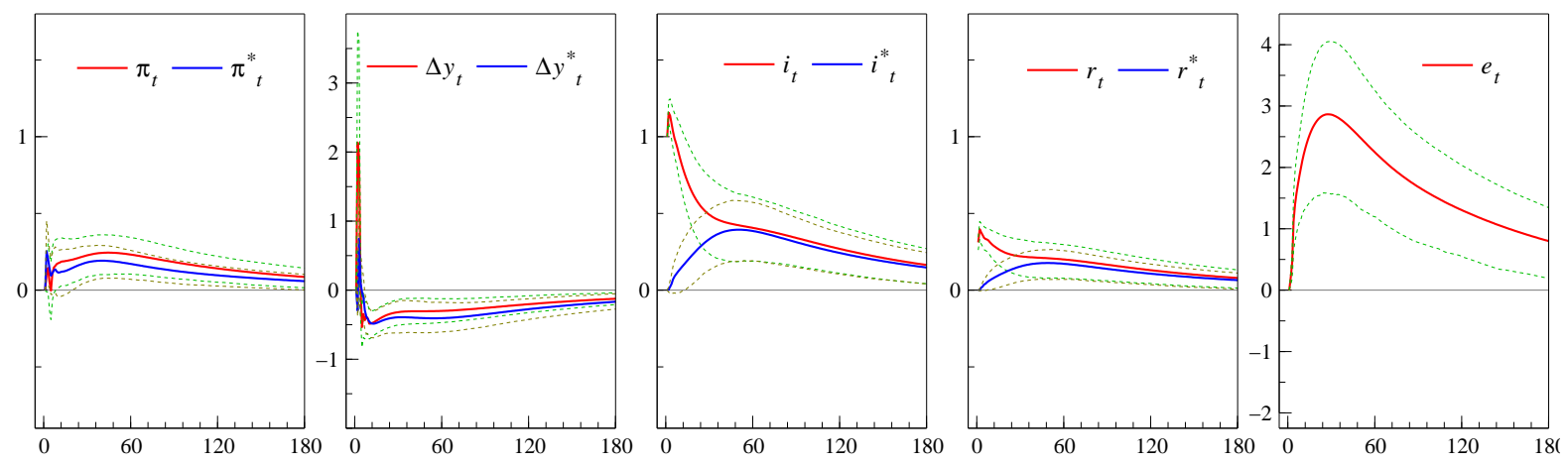

Figure 5 Responses to an idiosyncratic UK monetary policy shock in the baseline parsimonious SVECM, 95\% confidence bands. Annualized rates of interest, growth and inflation.

the short-term rate and to $18 \%$ of the shock for the bond rate. The gap between the US and UK shortterm rates is closed after 4 years. Taking the confidence bands into account already after 18 month. The interest rates in both countries return steadily back to the original level, although with considerable persistence, being still significantly different from zero after 15 years. After a short-lived initial rise, both output growth rates react negatively to the monetary policy shock, in line with economic theory. The inflation rates however show a positive response, the well known 'price puzzle'. The exchange rate appreciates steadily for several months, achieving a peak after 28 months, and finally depreciates thereafter. A clear pattern of delayed overshooting is present.

\subsection{An impulse response analysis of a monetary policy shock in the US}

The impulse responses of the system variables with regard to an one-percentage point increase in the monthly 3-month treasury bill return of the US are plotted in Figure 6.
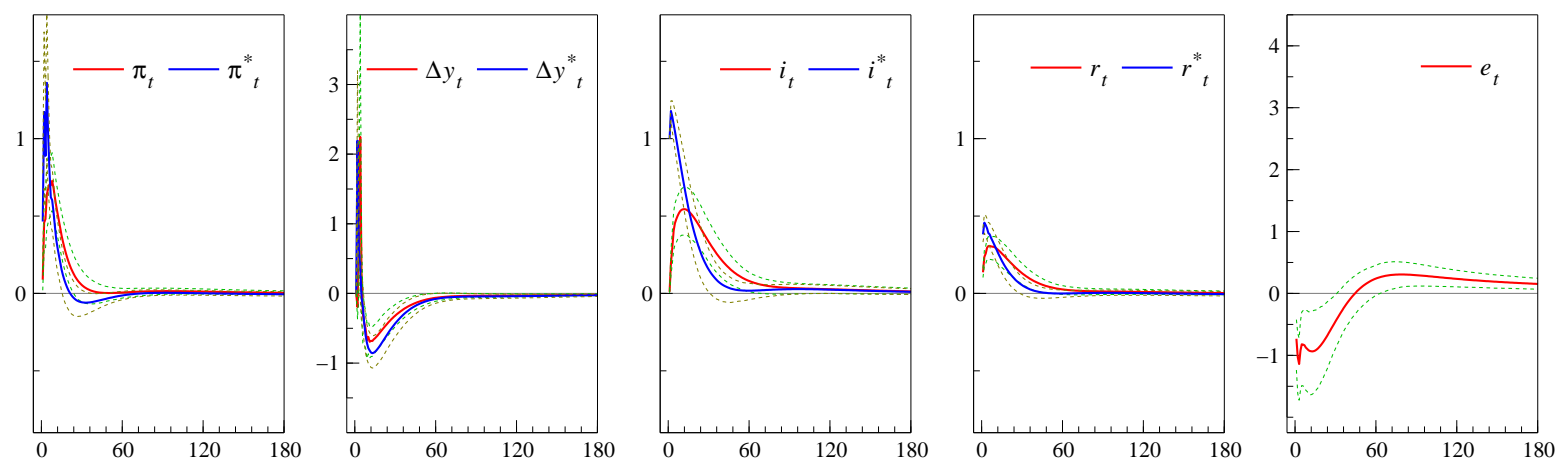

Figure 6 Responses to an idiosyncratic US monetary policy shock in the baseline parsimonious SVECM, 95\% confidence bands. Annualized rates of interest, growth and inflation. 
After a US monetary policy shock the US bond yield reacts contemporaneously with $38 \%$ of the size of the shock. So the Fed influences the long-term rates more strongly on impact than the Bank of England. The UK short-term interest rate only reacts on impact with $1 \%$ of the size of the shock, but reaches 54\% after 12 month. Thereafter the UK short-term rate is in fact larger than in the US. This strong mimicry is responsible for a higher bond yield in the UK than in the US one year after the US monetary shock. Just as in the UK case also here the responses of the output growth rates are negative and of the inflation rates positive. Overall the persistence in the system is much smaller in the case of the US monetary policy shock, with the variables being back to origin after 5 years. The exchange rate depreciates on impact but then appreciates to a level higher than at the beginning, what is due to the higher bond rate in the UK during the adjustment process. In total the reaction of the exchange rate is much smaller in the case of a US monetary policy shock, but delayed overshooting is not present, according to the baseline model. ${ }^{12}$

\subsection{Robustness of the impulse responses against model uncertainty}

As an alternative to the choice of a best model we take in the following all 48 PSVECM models into account that would result from a different design of the restricted $\mathbf{B}^{r}$ matrix in Table 9, corresponding to each possible form of the DAG consistent with the outcome of the graph-theoretical search for instantaneous causality in \$5.2. By doing so we preserve, additional to the estimation uncertainty considered before, knowledge about the model uncertainty present in the modelling process.

The first panel of Figure 7 depicts the exchange rate response to a UK monetary policy shocks in all 48 models (with the selected PSVECM in red) and the unweighted model average (in blue colour). The model simulations are quite similar to each other, with half of them revealing a pronouncedly larger degree of persistence. Due to the similarity of the models we refrain from trimming. Likewise no weighting scheme is employed due to only minor differences in the penalized fit of models when measured by the usual information criteria. With this approach we take model uncertainty into account, yet the results expressed before do not change qualitatively. It is worth noting that the selected model is at the lower end of the estimated responses with a peak response of 2.9 per cent versus 3.35 for the model average and 4.04 at maximum (which however are within the 95\% confidence band reported in Figure 5).

When taking all 48 models into account in the US case, see the second panel in Figure 7, half of the models display a sudden jump of the exchange rate while the rest show a delayed overshooting response. The models with the delayed overshooting response are these where the exchange rate feeds contemporaneously into the US short term interest rate equation. The exchange rate is not significant in the US interest rate equation, with p-values between 0.13 to 0.91 depending on specification of this equation, while the US short term interest rate is highly significant in the exchange rate equation. The model average shows a sudden jump with half the size of the baseline model but taking model uncertainty into account, a confidence band would include the zero line, however the average model offers the possibility of an appreciation of the Dollar on impact. The maximum peak appreciation of the Dollar in the average model is after 16 month, considerably earlier as in the case of a Bank of England shock with 34 month.

\footnotetext{
${ }^{12}$ To be precise the peak response is achieved 2 month after the monetary policy shock. But the main appreciation happens on impact.
} 

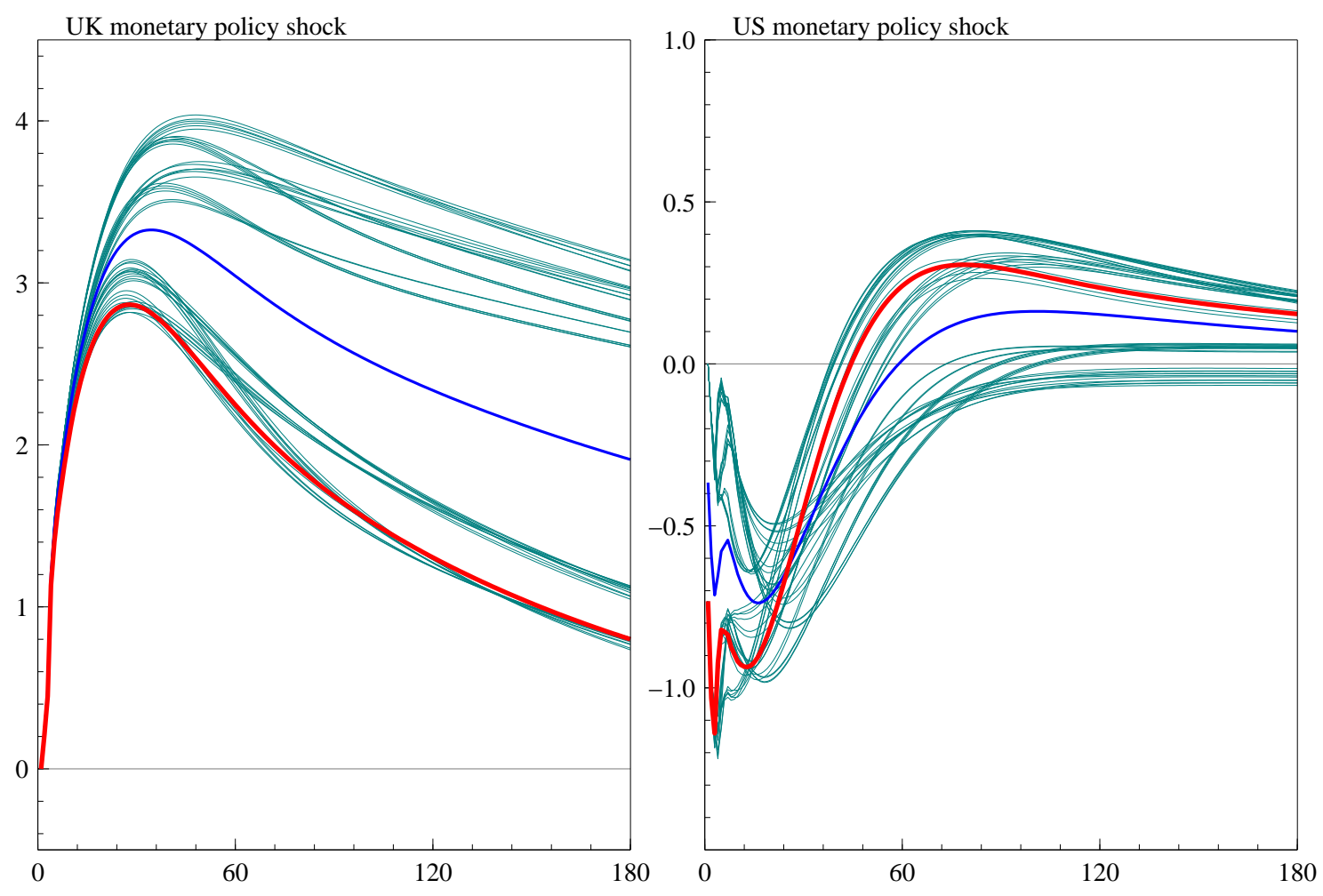

Figure 7 Robustness of the exchange rate response under model uncertainty.

Impulse responses for all 48 PSVECM with the baseline model in red and the model average in blue

\subsection{Analysing the impact of the price puzzle}

As the impulse responses show the signs of a price puzzle, an adverse reaction of inflation following a short-term interest rate shock, we are evaluating the relative importance of the price puzzle for the emergence of the delayed overshooting puzzle. In order to dissect the contribution of the price puzzle for the impulse responses of the exchange rate with regard to the monetary policy shocks, we run a thought experiment in which the feedback chains from the real sector of the economy, $\left(\pi_{t}, \pi_{t}^{*}, \Delta y_{t}, \Delta y_{t}^{*}\right)^{\prime}$, to the financial markets in form of $\left(i_{t}, i_{t}^{*}, r_{t}, r_{t}^{*}, e_{t}\right)^{\prime}$ are broken. In other words, we rerun the impulse response analysis while fixing inflation and output. The results of this experiment are shown in Figure 8. We can see that the exchange rate movements are qualitatively unchanged when discarding the feedback from the real economy. These findings demonstrate that the price puzzle does not invalidate the delayed overshooting results of the paper. As the price puzzle does not cause the delayed overshooting puzzle, the presence of a delayed overshooting puzzle should be invariant to model variations not exhibiting the price puzzle.

\subsection{Analysing the impact of the sample choice}

Kim et al. (2014) find that the phenomenon of delayed overshooting is mostly present in the Volcker era. In their analysis they focuss on sub-periods: the pre-Volcker, Volcker, and post-Volcker eras, where the Volcker era is spaning from 1979M08 to 1987M12. They find an appreciation on impact after a monetary policy shock for a sample starting at 1988 . Following this result, we analyse whether the exchange rate 

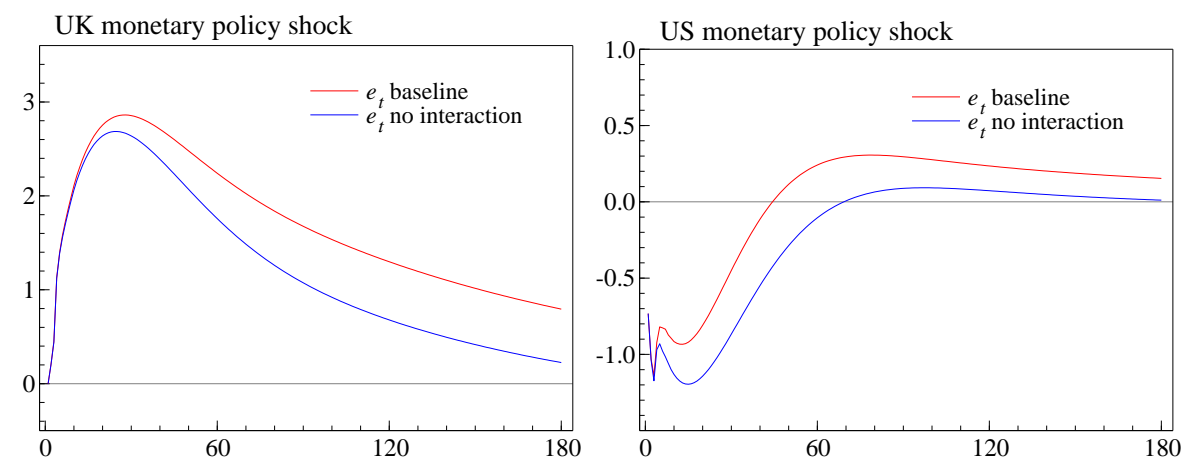

Figure 8 Impulse responses of the exchange rate to a monetary policy shock in the baseline model and the model without feedback from the real sector of the economy

responses are depending on the sample choice. By estimating our model for the post-Volcker era, we do not find major differences in the responses of the exchange rate to monetary policy shocks, see Figure 9. The findings of Kim et al. (2014) seem not to be critical for our data set.
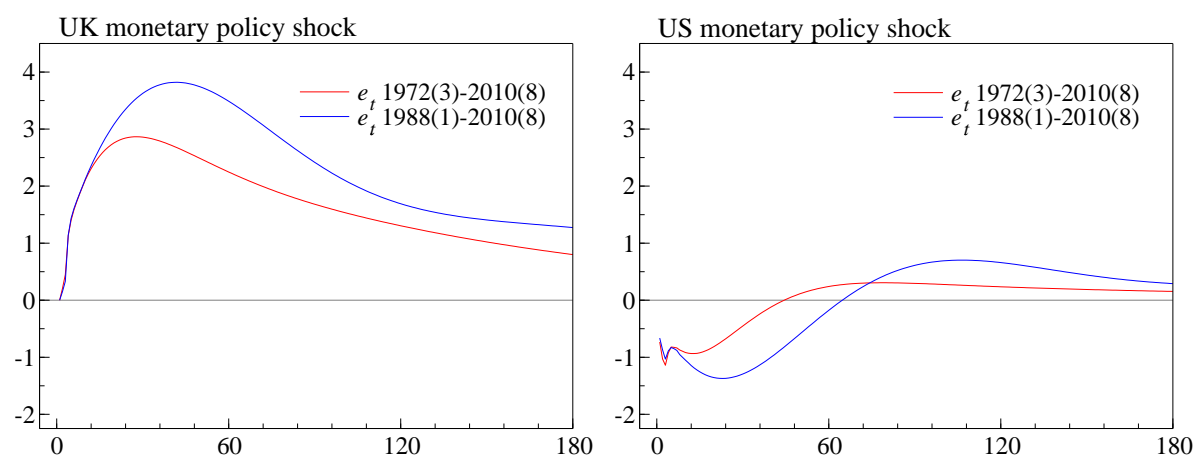

Figure 9 Impulse responses of the exchange rate to a monetary policy shock in the model with full sample and with a post-Volcker era sample starting 1988M1

\section{Conclusion}

The aim of this study was to construct a balanced UK-US two-country model to investigate the presence of a 'delayed overshooting puzzle'. The impulse response analysis discussed in the previous section found a delayed overshooting in respect to a Bank of England shock but an immediate response to a Fed surprise, with the exchange rate response larger in size in the former case. Even more strikingly are the differences in the long run: The persistence of the response after a UK shock is mirrored by a sign reversal in case of a US shock due to an overshooting adjustment process in the UK interest rate. The overwhelming evidence of asymmetry in the exchange rate adjustment depending on the geographic source of the shock demonstrate the need for a balanced two- or multi-country approach. A rigorous analysis in research to this issue is required, that should contribute to an explanation of the conflicting 
results of the literature.

However, an unrestricted two-country cointegrated VAR models would suffer from the curse of dimensionality. So researchers tend to restrict their analysses to a small number of variables. To overcome this limitation we proposed a modelling approach allowing to split the analysis of the long-run into two subsystems: a country-difference and a country-average system. Separability requires symmetry of the two countries, see Krolzig and Heinlein (2013). For the short-run this was rejected. Thus, the full 9-dimensional system has been modelled to determine the short-run and the contemporaneous effects, using the equilibrium correction terms from the earlier two subsystems. For the econometric model selection we proposed a data-driven approach combining a likelihood based cointegration analysis with a graph-theoretic search for instantaneous causal relations and an automatic general-to-specific approach for the selection of a parsimonious structural vector equilibrium correction model. Collectively putting these elements together, we believe to have a strong programme of how to set up empirical two-country models. 


\section{References}

Aoki, M. (1981). Dynamic analysis of open economies. New York: Academic Press. 1, 2, 4, 5, 9

Benkwitz, A., H. Lütkepohl, and J. Wolters (2001). Comparison of bootstrap confidence intervals for impulse responses of German monetary systems. Macroeconomic Dynamics 5, 81-100. 20

Bjørnland, H. C. (2009). Monetary policy and exchange rate overshooting: Dornbusch was right after all. Journal of International Economics 79, 64 - 77. 2, 3

Bouakez, H. and M. Normandin (2010). Fluctuations in the foreign exchange market: How important are monetary policy shocks? Journal of International Economics 81, 139-153. 2

Campos, J., D. F. Hendry, and H.-M. Krolzig (2003). Consistent model selection by an automatic Gets approach. Oxford Bulletin of Economics and Statistics 65, 803-819. 20

Cushman, D. O. and T. Zha (1997). Identifying monetary policy in a small open economy under flexible exchange rates. Journal of Monetary Economics 39, 433 - 448. 2, 3

Demiralp, S. and K. D. Hoover (2003). Searching for the causal structure of a Vector Autoregression. Oxford Bulletin of Economics and Statistics 65, 745-767. 7

Dornbusch, R. (1976). Expectations and exchange rate dynamics. The Journal of Political Economy 84, 1161-76. 2

Eichenbaum, M. and C. Evans (1995). Some empirical evidence on the effects of shocks to monetary policy on exchange rates. The Quarterly Journal of Economics 110, 975-1009. 2, 3

Faust, J. and J. H. Rogers (2003). Monetary policy's role in exchange rate behavior. Journal of Monetary Economics 50, 1403. 2

Frankel, J. A. (1979). On the Mark: A theory of floating exchange rates based on real interest differentials. American Economic Review 69, 610 - 622. 2

Gonzalo, J. and C. W. J. Granger (1995). Estimation of Common Long-Memory Components in Cointegrated Systems. Journal of Business \& Economic Statistics 13, 27-35. 16

Granger, C. W. J. and N. Haldrup (1997). Separation in cointegrated systems and persistent-transitory decompositions. Oxford Bulletin of Economics and Statistics 59, 449-463. 16

Grilli, V. and N. Roubini (1996). Liquidity models in open economies: Theory and empirical evidence. European Economic Review 40, 847 - 859. 2

Hall, P. (1992). The Bootstrap and Edgeworth Expansion. New York: Springer. 20

Heinlein, R. and H.-M. Krolzig (2012). Effects of monetary policy on the US Dollar/UK Pound exchange rate. Is there a 'delayed overshooting puzzle'? Review of International Economics 20, 443467. $2,4,7,8,10$

Hendry, D. F. and H.-M. Krolzig (2005). The properties of automatic GETS modelling. Economic Journal 115, C62-C98. 20 
Hoover, K. D., S. Demiralp, and S. J. Perez (2009). Empirical identification of the vector autoregression: The causes and effects of U.S. M2. In J. Castle and N. Shephard (Eds.), The Methodology and Practice of Econometrics: A Festschrift in Honour of David F. Hendry, pp. 37-58. Oxford: Oxford University Press. 7

Johansen, S. (1995). Likelihood-Based Inference in Cointegrated Vector Autoregressive Models. Oxford: Oxford University Press. 11, 14, 16

Juselius, K. (2006). The cointegrated VAR model. Oxford: Oxford University Press. 4, 7, 12

Kim, S. and N. Roubini (2000). Exchange rate anomalies in the industrial countries: A solution with a structural VAR approach. Journal of Monetary Economics 45, 561 - 586. 2, 3

Kim, S.-H., S. Moon, and C. Velasco (2014). Delayed overshooting: It's an 80s puzzle. Working paper No 1410, Centre for Dynamic Macroeconomic Analysis, University of St Andrews. 2, 23, 24

Konishi, T., V. A. Ramey, and C. W. J. Granger (1993). Stochastic trends and short-run relationships between financial variables and real activity. Working Paper 4275, NBER Working Paper, Cambridge, MA. 16

Krolzig, H.-M. (2003). General-to-specific model selection procedures for structural vector autoregressions. Oxford Bulletin of Economics and Statistics 65, 769-801. 7, 8, 19

Krolzig, H.-M. and R. Heinlein (2013). Symmetry and Separability in Two-Country Cointegrated VAR Models: Representation and Testing. Working paper, School of Economics, University of Kent, Canterbury. 5, 25

Linnemann, L. and A. Schabert (2015). Liquidity premia and interest rate parity. Journal of International Economics 97, 178-192. 3

Pearl, J. (2000). Causality: Models, Reasoning, and Inference. Cambridge: Cambridge University Press. 7

Pesaran, M. H., T. Schuermann, and S. M. Weiner (2004). Modeling regional interdependencies using a global error-correcting macroeconometric model. Journal of Business and Economic Statistics 22, 129-162. 4

Romer, C. and D. Romer (2004). A new measure of monetary shocks: Derivation and implications. American Economic Review 94, 1055-84. 2

Scholl, A. and H. Uhlig (2008). New evidence on the puzzles: Results from agnostic identification on monetary policy and exchange rates. Journal of International Economics 76, 1 - 13. 2

Spirtes, P., C. Glymour, and R. Scheines (2001). Causation, Prediction, and Search (2nd ed.). Cambridge, MA: MIT Press. 7

Spirtes, P., R. Scheines, J. Ramsey, and C. Glymour (2005). Tetrad 4.3.3-0. Technical report, Carnegie Mellon University, http://www.phil.cmu.edu/tetrad. 7

Voss, G. and L. Willard (2009). Monetary policy and the exchange rate: Evidence from a two-country model. Journal of Macroeconomics 31, 708 - 720. 2, 3 


\section{A Appendix}

\section{A.1 Interest rate parities, the Fisher hypothesis and the term structure}

Figure 1 (third and fourth column) looks at the potential cointegration between the nominal $3 \mathrm{M}$ and $10 \mathrm{Y}$ interest rates in the UK and the US (blue and red lines) as well as the mean reversion of the interest rate differentials and averages. Due to the accommodating UK monetary policy in the 1970s, the longterm interest-rate differential shows clear signs of non-stationarity. As the UK short-term interest rates do not fully reflect the inflation problem of that time period, the short-term interest-rate differential conversely is a potential candidate for a cointegration relation. In contrast, both interest rate averages are non-stationary. ${ }^{13}$

Figure 10 (left and middle column) graphically evaluates the presence of a real interest rate parity,

$$
\rho_{t}-\rho_{t}^{*}=\left(i_{t}-\mathrm{E}_{t} \pi_{t+1}\right)-\left(i_{t}^{*}-\mathrm{E}_{t} \pi_{t+1}^{*}\right) \sim I(0),
$$

using a naive measurement of inflation expectations by the current backward-looking rate of inflation:

$$
\rho_{t}=i_{t}-\mathrm{E}_{t} \pi_{t+1} \approx i_{t}-\Delta p_{t}
$$

Both the short-term and the long-term real interest rates for the UK and the US show a level shift at the time of the Volcker disinflation. Since then a downward trend is present. Overall, the real long-term interest rate differential is more likely to be stationary than the real short-term differential. The level shift in 1981 is also present in the real rate averages. So the preliminary evidence regarding the Fisher hypothesis is mixed.
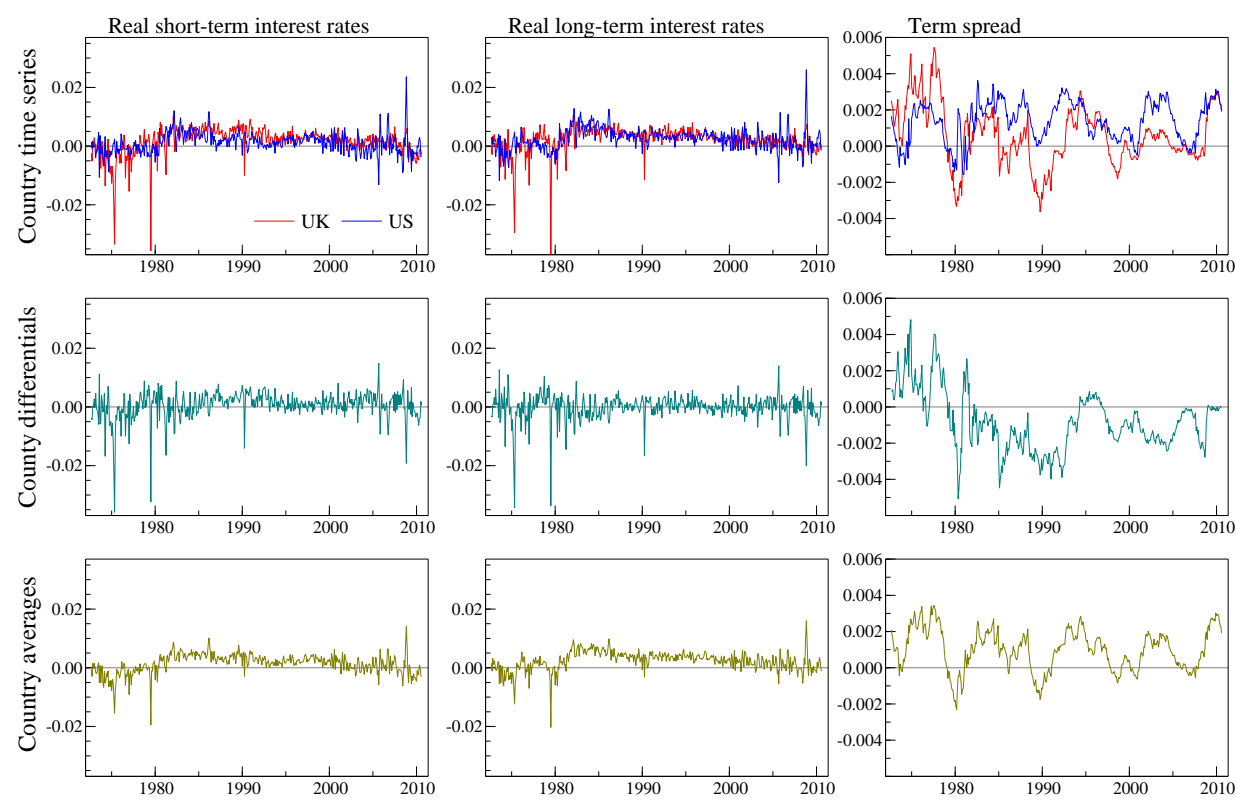

Figure 10 Real short- and long-term interest rates and the term spread

Finally, a strong contender for a cointegration relation emerges as the term spread as underpinned by

\footnotetext{
${ }^{13} \mathrm{An}$ ADF test for the long-term interest rate average rejects marginally a unit root in favour of trend stationarity. This, however, is highly sample dependent due to the 30 year old bull market for long-term government bonds since 1981 .
} 
the expectations hypothesis of the term structure (EHT). According to which, the yield of a zero bond with a maturity of $T$ periods should equal the average of the expected one-period interest rates ${ }^{14}$ plus a potential risk premium, $\phi_{t}$ :

$$
r_{t}=\frac{1}{T} \sum_{j=0}^{T-1} \mathrm{E}_{t} i_{t+j}+\phi_{t} .
$$

After substracting $i_{t}$ from both sides and rearranging the right hand side we get the equation (24):

$$
r_{t}-i_{t}=\frac{1}{T} \sum_{j=0}^{T-1} \sum_{h=1}^{j} \mathrm{E}_{t} \Delta i_{t+h}+\phi_{t} .
$$

If the short-term rate and the long-term rate are $I(1)$ variables and the risk premium is a stationary process, it follows from (24) that $r_{t}-i_{t} \sim I(0)$ since $\Delta i_{t}$ is $I(0)$ and a finite sum of stationary variables is stationary. The term spread for the UK and the US, as well as their differences and averages is plotted in the last column of Figure 10. While the term spread appears potentially stationary for the US, this clearly is not the case for the UK. Hence we should not expect that short and long-term interest rate differentials cointegrate, but the cointegration between short and long-term interest averages may hold.

\section{A.2 Purchasing power and uncovered interest parity}

As the data did not support the purchasing power parity (PPP) for our sample period, we included in our analysis the inflation rates of the UK and US but not the price levels. No evidence was found for the nominal exchange rate to be cointegrated with the relative price level (see upper-left panel of Figure 11) or the mean reversion of the real exchange rate $s_{t}=e_{t}+p_{t}-p_{t}^{*}$ (see upper-right panel of Figure 11). The Pound Sterling appreciated in real terms by more than $70 \%$ from the end of 1984 to the beginning of 2008, which can not be explained within the set of macro variables considered here. We therefore leave this issue for further investigations.

The exchange determination therefore has to be base on the uncovered interest rate parity (UIP), which requires that the expected return on the domestic asset, in equilibrium, is equal to expected return, measured in the home currency, on a foreign asset with otherwise identical characteristics. For a oneperiod bond, this implies:

$$
i_{t}=i_{t}^{*}-\mathrm{E}_{t} \Delta e_{t+1} .
$$

Under rational expectations, there are no systematic forecast errors and equation (25) can be rewritten as:

$$
\xi_{t}=i_{t}^{d}+\Delta e_{t+1}
$$

where $\xi_{t}$ is a martingale difference sequence and measures the excess return of the UK one-period bond. ${ }^{15}$ The realized excess returns over the sample period and their cumulation can be seen in the lower panels of Figure 11.

\footnotetext{
${ }^{14}$ Please note that while in theoretical discussions the short-term interest rate is that of one-period bonds, in the empirical part we work with 3-month interest rates due to data availability.

${ }^{15}$ Please note that the $3 \mathrm{M}$ interest rate is used here as a proxy of the non-available one-period interest rate. Thus, bond price changes have not been taken into account.
} 

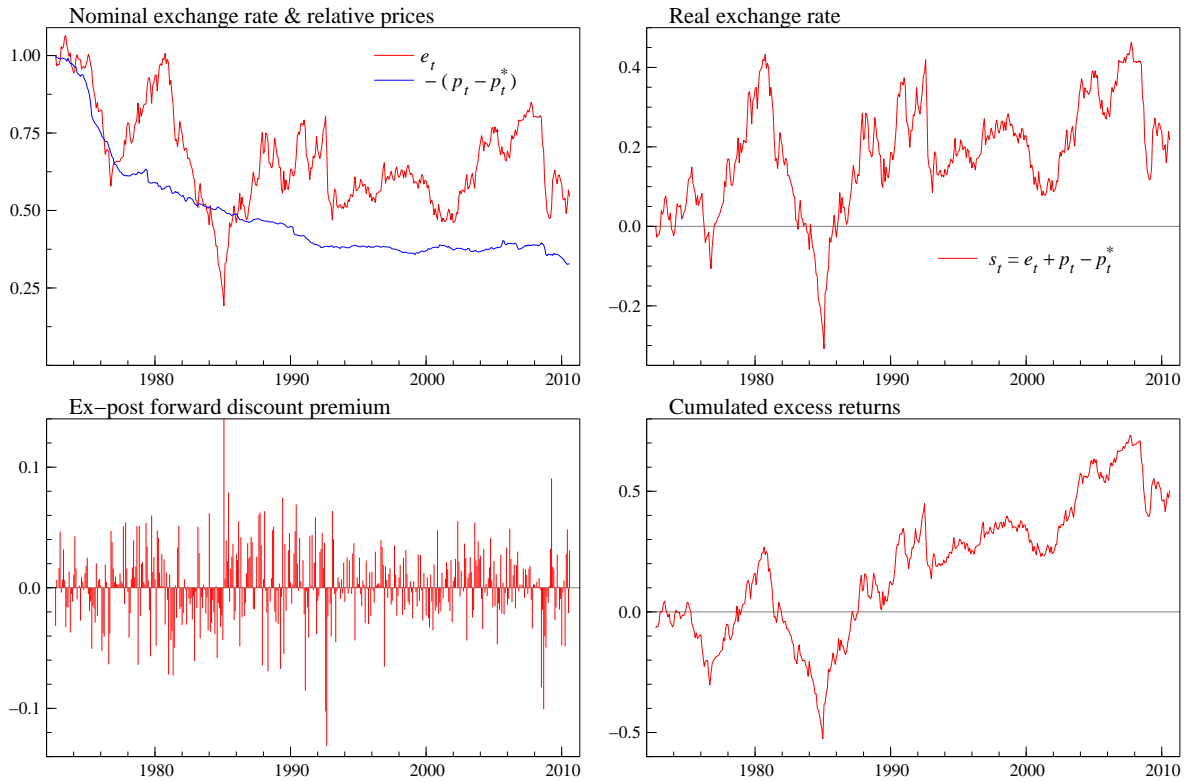

Figure 11 Deviations from PPP and UIP. Top: Nominal exchange rate, relative prices and the real exchange rate. Bottom: Ex-post excess returns and their cumulation 


\section{B Appendix}

Table 10 Misspecification tests for the unrestricted VAR(4) of the country difference model

\begin{tabular}{lcccccc}
\hline \hline Test & & $\pi_{t}^{d}$ & $\Delta y_{t}^{d}$ & $i_{t}^{d}$ & $r_{t}^{d}$ & \multicolumn{1}{c}{$e_{t}$} \\
\hline AR 1-13 & $\mathrm{F}(13,428)$ & 0.947 & 1.473 & 1.438 & 1.167 & 1.182 \\
& & {$[0.530]$} & {$[0.124]$} & {$[0.138]$} & {$[0.302]$} & {$[0.289]$} \\
Normality & $\chi^{2}(2)$ & $149.11^{* *}$ & 0.27 & $125.83^{* *}$ & $30.20^{* *}$ & $39.70^{* *}$ \\
& & {$[0.000]$} & {$[0.875]$} & {$[0.000]$} & {$[0.000]$} & {$[0.000]$} \\
ARCH 1-13 & $\mathrm{F}(13,415)$ & 1.591 & 1.660 & $7.918^{* *}$ & $5.371^{* *}$ & $1.816^{*}$ \\
& & {$[0.085]$} & {$[0.067]$} & {$[0.000]$} & {$[0.000]$} & {$[0.039]$} \\
Hetero & $\mathrm{F}(40,400)$ & $2.300^{* *}$ & 0.908 & $2.742^{* *}$ & $3.394^{* *}$ & 1.386 \\
& & {$[0.000]$} & {$[0.634]$} & {$[0.000]$} & {$[0.000]$} & {$[0.065]$} \\
\hline \hline \multicolumn{5}{c}{ ** significant at 1\% level, ${ }^{*}$ significant at 5\% level. } \\
\end{tabular}

Table 11 Testing for weak exogeneity in the country difference model

\begin{tabular}{cccccc}
\hline \hline & $\pi_{t}^{d}$ & $\Delta y_{t}^{d}$ & $i_{t}^{d}$ & $r_{t}^{d}$ & $e_{t}$ \\
\hline$\chi^{2}(4)$ & - & 136.14 & 15.97 & 2.07 & 14.84 \\
& {$[0.00]$} & {$[0.00]$} & {$[0.00]$} & {$[0.72]$} & {$[0.00]$} \\
\hline \hline
\end{tabular}

Table 12 Cointegration vectors and loadings of the country difference model, $t$-values in brackets

\begin{tabular}{|c|c|c|c|c|c|c|c|c|}
\hline & \multicolumn{4}{|c|}{$\overline{\text { Cointegration vectors }}$} & \multicolumn{4}{|c|}{ Loadings } \\
\hline & $\boldsymbol{\beta}_{1}^{d}$ & $\boldsymbol{\beta}_{2}^{d}$ & $\beta_{3}^{d}$ & $\boldsymbol{\beta}_{4}^{d}$ & $\boldsymbol{\alpha}_{1}^{d}$ & $\boldsymbol{\alpha}_{2}^{d}$ & $\boldsymbol{\alpha}_{3}^{d}$ & $\boldsymbol{\alpha}_{4}^{d}$ \\
\hline$\pi_{t}^{d}$ & 0 & 0 & -1 & 0 & $\begin{array}{r}0.025 \\
(0.62)\end{array}$ & $\begin{array}{r}0.118 \\
(0.93)\end{array}$ & $\begin{array}{c}0.736^{* *} \\
(9.80)\end{array}$ & $\begin{array}{r}0.0006 \\
(0.45)\end{array}$ \\
\hline$\Delta y_{t}^{d}$ & 1 & 0 & 0 & 0 & $\begin{array}{l}-1.230^{* *} \\
(-12.10)\end{array}$ & $\begin{array}{r}-0.159 \\
(-0.49)\end{array}$ & $\begin{array}{r}0.186 \\
(0.98)\end{array}$ & $\begin{array}{r}-0.0002 \\
(-0.16)\end{array}$ \\
\hline$i_{t}^{d}$ & 0 & 1 & 0 & 0 & $\begin{array}{r}0.004 \\
(0.62)\end{array}$ & $\begin{array}{c}-0.073^{* *} \\
(-3.96)\end{array}$ & $\begin{array}{r}0.006 \\
(0.55)\end{array}$ & $\begin{array}{r}-0.0002 \\
(-1.26)\end{array}$ \\
\hline$r_{t}^{d}$ & 0 & 0 & & $\begin{array}{r}87.2 \\
(4.0)\end{array}$ & $\begin{array}{r}-0.001 \\
(-0.17)\end{array}$ & $\begin{array}{r}-0.011 \\
(-1.05)\end{array}$ & $\begin{array}{r}0.004 \\
(0.64)\end{array}$ & $\begin{array}{r}0.0001 \\
(0.83)\end{array}$ \\
\hline$e_{t}$ & 0 & 0 & 0 & 1 & $\begin{array}{r}-0.191 \\
(-0.67)\end{array}$ & $\begin{array}{r}-0.074 \\
(-0.08)\end{array}$ & $\begin{array}{r}0.993 \\
(1.89)\end{array}$ & $\begin{array}{c}-0.031^{* *} \\
(-3.20)\end{array}$ \\
\hline
\end{tabular}

${ }^{* *}$ significant at $1 \%$ level, ${ }^{*}$ significant at $5 \%$ level. 
Table 13 Misspecification tests for the unrestricted VAR(3) of the country average model

\begin{tabular}{lccccc}
\hline \hline Test & & \multicolumn{1}{c}{$\pi_{t}^{a}$} & \multicolumn{1}{c}{$\Delta y_{t}^{a}$} & \multicolumn{1}{c}{$i_{t}^{a}$} & \multicolumn{1}{c}{$r_{t}^{a}$} \\
\hline AR 1-13 & $\mathrm{F}(13,436)$ & $2.877^{* *}$ & $2.142^{*}$ & $2.084^{*}$ & 0.932 \\
& & {$[0.001]$} & {$[0.011]$} & {$[0.014]$} & {$[0.520]$} \\
Normality & $\chi^{2}(2)$ & $254.13^{* *}$ & $16.15^{* *}$ & $223.49^{* *}$ & $25.92^{* *}$ \\
& & {$[0.000]$} & {$[0.000]$} & {$[0.000]$} & {$[0.000]$} \\
ARCH 1-13 & $\mathrm{F}(13,423)$ & $2.790^{* *}$ & 1.127 & $6.007^{* *}$ & $4.508^{* *}$ \\
& & {$[0.001]$} & {$[0.334]$} & {$[0.000]$} & {$[0.000]$} \\
Hetero & $\mathrm{F}(24,424)$ & $2.325^{* *}$ & $2.525^{* *}$ & $7.408^{* *}$ & $6.747^{* *}$ \\
& & {$[0.001]$} & {$[0.000]$} & {$[0.000]$} & {$[0.000]$} \\
\hline \hline
\end{tabular}

** significant at $1 \%$ level, ${ }^{*}$ significant at $5 \%$ level.

Table 14 Testing for weak exogeneity in the country average model

\begin{tabular}{ccccc}
\hline \hline & $\pi_{t}^{a}$ & $\Delta y_{t}^{a}$ & $i_{t}^{a}$ & $r_{t}^{a}$ \\
\hline$\chi^{2}(3)$ & 36.35 & - & 7.54 & 4.76 \\
& {$[0.00]$} & {$[0.00]$} & {$[0.06]$} & {$[0.19]$} \\
\hline \hline
\end{tabular}

Table 15 Cointegration vectors and loadings of the country average model, $t$-values in brackets

\begin{tabular}{lccrrrr}
\hline \hline & \multicolumn{3}{c}{ Cointegration vectors } & \multicolumn{3}{c}{ Loadings } \\
& $\boldsymbol{\beta}_{1}^{a}$ & $\boldsymbol{\beta}_{2}^{a}$ & $\boldsymbol{\beta}_{3}^{a}$ & $\boldsymbol{\alpha}_{1}^{a}$ & $\boldsymbol{\alpha}_{2}^{a}$ & $\boldsymbol{\alpha}_{3}^{a}$ \\
\hline$\pi_{t}^{a}$ & 0 & -1 & 0 & -0.022 & $0.251^{* *}$ & -0.055 \\
& & & & $(-0.80)$ & $(5.95)$ & $(-0.54)$ \\
$\Delta y_{t}^{a}$ & 1 & 0 & 0 & $-0.619^{* *}$ & 0.136 & $0.838^{* *}$ \\
& & & & $(-9.45)$ & $(1.35)$ & $(3.46)$ \\
$i_{t}^{a}$ & 0 & 0 & -1 & 0.008 & -0.006 & 0.023 \\
& & & & $(1.90)$ & $(-0.95)$ & $(1.56)$ \\
$r_{t}^{a}$ & 0 & 1 & 1 & 0.002 & -0.009 & -0.011 \\
& & & & $(0.70)$ & $(-1.93)$ & $(-1.07)$ \\
\hline \hline
\end{tabular}

${ }^{* *}$ significant at $1 \%$ level, ${ }^{*}$ significant at $5 \%$ level. 